\title{
First chemoenzymatic stereodivergent synthesis of both enantiomers of promethazine and ethopropazine
}

\author{
Paweł Borowiecki ${ }^{*}$ Daniel Paprocki and Maciej Dranka
}

\author{
Full Research Paper \\ Address: \\ Warsaw University of Technology, Faculty of Chemistry, \\ Noakowskiego St. 3, 00-664 Warsaw, Poland \\ Email: \\ Paweł Borowiecki - pawel_borowiecki@onet.eu \\ ${ }^{*}$ Corresponding author \\ Keywords: \\ ethopropazine; lipase-catalyzed kinetic resolution; Mosher \\ methodology; promethazine; stereodivergent synthesis
}

Beilstein J. Org. Chem. 2014, 10, 3038-3055.

doi:10.3762/bjoc. 10.322

Received: 03 September 2014

Accepted: 01 December 2014

Published: 18 December 2014

Associate Editor: J. Aubé

() 2014 Borowiecki et al; licensee Beilstein-Institut.

License and terms: see end of document.

\begin{abstract}
Enantioenriched promethazine and ethopropazine were synthesized through a simple and straightforward four-step chemoenzymatic route. The central chiral building block, 1-(10H-phenothiazin-10-yl)propan-2-ol, was obtained via a lipase-mediated kinetic resolution protocol, which furnished both enantiomeric forms, with superb enantioselectivity (up to $E=844$ ), from the racemate. Novozym 435 and Lipozyme TL IM have been found as ideal biocatalysts for preparation of highly enantioenriched phenothiazolic alcohols (up to $>99 \%$ ee), which absolute configurations were assigned by Mosher's methodology and unambiguously confirmed by XRD analysis. Thus obtained key-intermediates were further transformed into bromide derivatives by means of $\mathrm{PBr}_{3}$, and subsequently reacted with appropriate amine providing desired pharmacologically valuable $(R)$ - and $(S)$-stereoisomers of title drugs in an ee range of $84-98 \%$, respectively. The modular amination procedure is based on a solvent-dependent stereodivergent transformation of the bromo derivative, which conducted in toluene gives mainly the product of single inversion, whereas carried out in methanol it provides exclusively the product of net retention. Enantiomeric excess of optically active promethazine and ethopropazine were established by HPLC measurements with chiral columns.
\end{abstract}

\section{Introduction}

Since enantiomorphs of biologically active compounds exhibit significant differences in their pharmacokinetic and pharmacodynamic behavior, optical purity of chiral drugs has emerged as an important factor in efficacy and safety of their application [1-3]. Thus, the development of an effective, inexpensive and environmentally friendly method for the formulation of single enantiomers still remains a challenging task for organic chemists. Nowadays, classical chemical manufacturing technologies are increasingly displaced by pure biotechnological processes or biotransformations coupled with chemical operations [4-10]. The main advantages of these impactful techniques are high substrate specificity as well as regio- and stereoselectivity of the reaction [11-13]. In addition, the easy handling (not involving the use of a complex chemical apparatus), possi- 
bility of catalyst recovery, mild experimental (room temperature, atmospheric pressure, etc.) and non-hazardous environmental conditions as well as organic solvent-, moisture- and airstability make tandem chemoenzymatic processes attractive for both: laboratory and industrial applications. Since enzymecatalyzed processes provide an access to enantiomerically enriched compounds, they became an extremely practical tool for chemistry and biotechnology [14-21]. A vast number of publications have recently shown the enormous potential of enzymatic bioconversions in the synthesis of high value-added active ingredients and useful chiral building blocks for pharmaceutical or fine-chemical industries [13,22-31]. Among the enzymes applied, lipases occupy a prominent place in advanced organic synthesis as biocatalysts of chiral recognition [32-39].

Nowadays, nervous and mental health problems mainly caused by the pace of life and the rapid development of civilization are very prevalent and dangerous diseases. An irregular and unsanitary lifestyle adversely affects the central nervous system resulting in neuroses and psychiatric disorders. Among the antipsychotic medications phenothiazine derivatives [40,41], and especially promethazine, widely known by its brand name Phenergan ${ }^{\circledR}$, hold well deserved place. As it posses excellent antihistaminic activity ( $\mathrm{H}_{1}$-antagonist) [42], pronounced antimuscarinic [43], anticholinergic [44], sedative, antiemetic and adrenergic blocking action as well as some local anesthetic properties [45], promethazine is approved for the effective therapy of various disorders clearly diverging from the original application. It has gained widespread usage in the treatment of allergic reactions, itching dermatitis, cough (when applied together with codeine or dextromethorphan), sleeplessness or symptoms of motion, morning and Ménière's sicknesses including nausea and vomiting. For over four decades it has been considered that both enantiomers of promethazine posses exactly the same therapeutic activities [46,47], and thus it was administered in clinical settings as racemate. However, recent findings have shown that the different physiological and pharmacological effects of the two enantiomers of promethazine are a fact, what makes this drug returned to the laboratories. For example, it has been determined that $(+)$-promethazine reduced the cytokine IL-6 production in histamine-stimulated cells to $90 \%$ while (-)-promethazine induced only $50 \%$ reduction in cytokine IL-6 production [48]. Moreover, Boland and McDonought $[49,50]$ found that preferably the $(+)$-enantiomer of promethazine is particularly effective in inhibiting the formation of bone resorbing cells (osteoclasts) thus providing a new class of agents useful for preventing or even treating bone loss, mainly associated with periodontitis and osteoporosis. Moreover, kinetic resolution of the enantiomers of the key intermediate 1-(10H-phenothiazin-10-yl)propan-2-ol may simultaneously provide access to another valuable compound in enan- tioenriched form, that is: ethopropazine (profenamine). In turn, this antidyskinetic drug has been widely used in clinical practice for over the past 30 years in the treatment of Parkinson's disease, although there is no data available regarding its pharmacokinetic properties in humans. Only one study on the mechanism of stereoselective interaction between butyrylcholinesterase $(\mathrm{BChE})$ and ethopropazine enantiomers was performed leading to the final conclusion that BChE possesses a significantly higher affinity for the $(R)$-configured ethopropazine [51]. In order to find whether ethopropazine displays stereoselectivity in its pharmacokinetics and exhibits different biological profiles of its stereoisomers, obtaining both enantiomers in more than analytical quantities is particularly desirable. Moreover, the racemic mixture of this pharmaceutical is commercially available, however it is sold at high price, as its production by standard synthetic procedures is time-consuming and laborious. Therefore, a low-cost, practical, and scalable method for the straightforward preparation of ethopropazine is still a great challenge.

To the best of our knowledge, heretofore no reports concerning the enzymatic preparative-scale synthesis of optically active promethazine and ethopropazine have been reported. Only enantioselective analytical methods towards enantioresolution of promethazine employing various chiral selectors including proteins, cyclodextrines, modified crown ethers or macrocyclic antibiotics have been proposed [52-56]. Other two reports $[57,58]$ containing information about ethopropazine enantiomers separation (mainly via fractional crystallization or column chromatography splitting of diastereomeric dibenzoyltartaric acid salts) have been described. Despite the abovementioned results, the availability of a scalable stereoselective procedure has, as far as we know, been deemed insufficient. We believe that the lipase-catalyzed resolution procedure presented herein, will be an interesting alternative to these published methods, and will open a novel route worth considering in multigram-scale synthesis of both aforementioned pharmaceuticals.

Therefore, the aim of this study was to take advantage of the extraordinary properties of enzyme catalysis and develop a new method based on lipase-mediated kinetic resolution (KR) of 1-(10H-phenothiazin-10-yl)propan-2-ol enantiomers, which combined with convenient chemical reactions could provide a simple and straightforward approach for the preparation of optically active promethazine and ethopropazine molecules, respectively.

\section{Results and Discussion}

Herein, we wish to present an original chemoenzymatic procedure for the enantioselective synthesis of promethazine 9 and 
ethopropazine 10. Most of our efforts during these studies have been focused toward extensive screening of the conditions for the lipase-catalyzed kinetic resolution of 1-(10H-phenothiazin10-yl)propan-2-ol racemate $( \pm)$-3. The other part of the work involved investigation of the enzymatic reactions stereoselectivity, which was accomplished by means of the assignment of the absolute configuration of the resolved enantiopure alcohol $(S)-(+)-5$ determined by a modified Mosher's methodology, and was unambiguously confirmed by X-ray diffraction analysis. Optically active intermediates $(S)-(+)-5$ and $(R)-(-)-7$ achieved in this manner were subsequently transformed into active pharmaceuticals $\mathbf{9}$ and $\mathbf{1 0}$ as $(R)$ - and $(S)$-enantiomers afforded in high enantiopurity (84-98\% ee) (Scheme 1) and in a stereodivergent fashion.

\section{Synthesis of the racemic $1-(10 \mathrm{H}$-pheno- thiazin-10-yl)propan-2-ol ( \pm -) 3 and its acyl esters $( \pm)-\mathbf{4 a - c}$}

In the first step, racemic 1-(10H-phenothiazin-10-yl)propan-2ol $( \pm)$-3 was synthesized according to the method described by Clement et al. [59], in which propylene oxide (2) was regiose- lectively opened by phenothiazine (1) in the presence of $n$-butyllithium ( $n$-BuLi) at ambient temperature providing desired alcohol $( \pm)-3$ in $64-77 \%$ yield depending on the applied scale and the purification method (see Supporting Information File 1). Paradoxically, the product was obtained in higher yield when the reaction was performed on a bigger scale, and when the product was isolated by vacuum distillation instead of column chromatography $\left(\mathrm{SiO}_{2}\right)$. It is worth to note, that the preparation of $( \pm)-\mathbf{3}$ was very problematic. Before we decided to repeat the reaction procedure proposed by Clement, we attempted to obtain $( \pm)$-3 by adopting the original methodology reported by Dahlbom [60]. Unfortunately, quite surprisingly the reaction conducted by this approach, which assumed usage of sodium amide $\left(\mathrm{NaNH}_{2}\right)$ as a base, produced enormous amounts of byproducts, which significantly hampered both the isolation and purification procedures. The same phenomenon was observed if sodium hydride $(\mathrm{NaH})$ was utilized instead of $\mathrm{NaNH}_{2}$ under similar reaction conditions, what suggests that this particular process is most probably inaccessible through the sodium salt of phenothiazine (1) due to multiple substitution at aromatic ring carbon atoms and some other byproducts of the

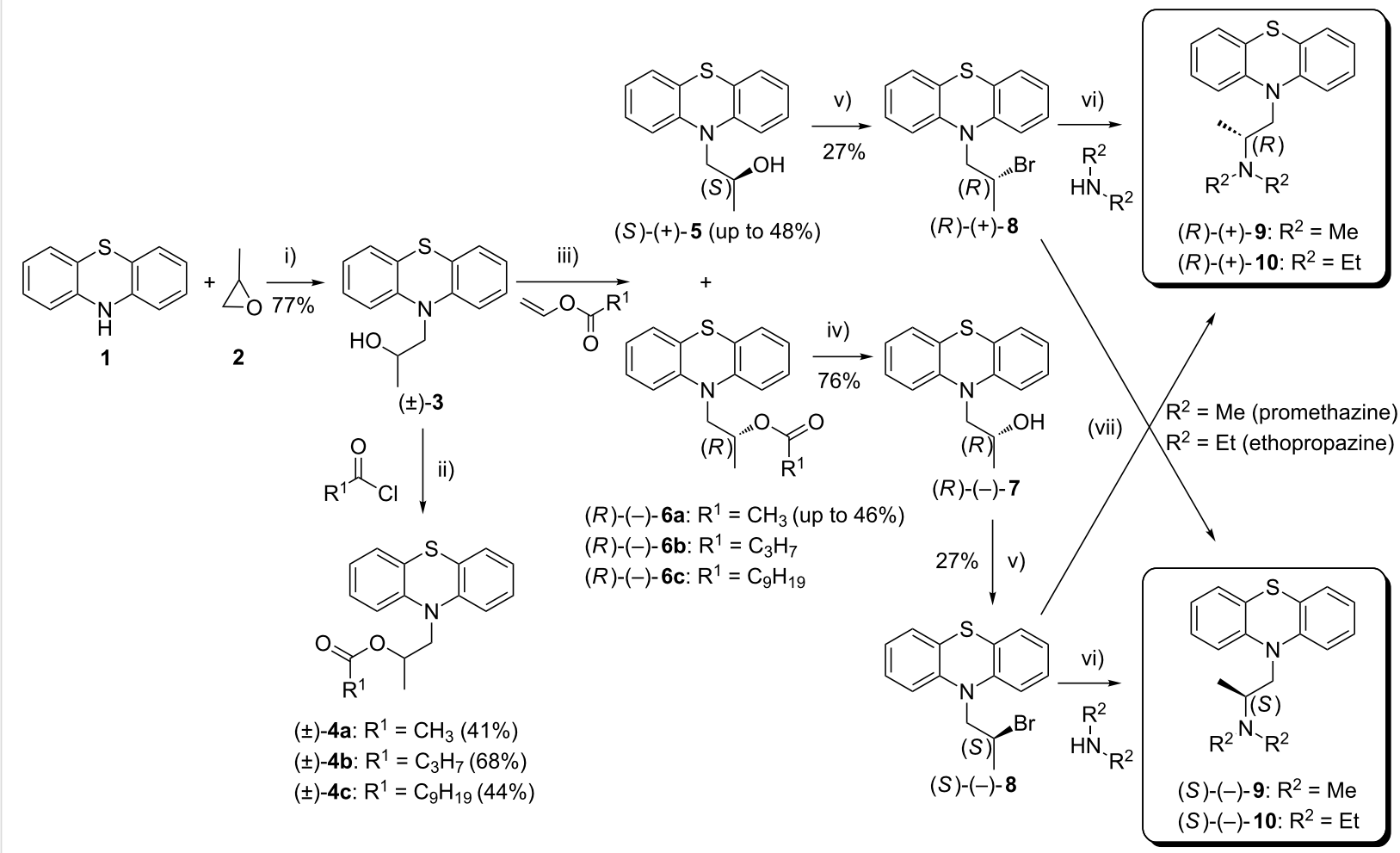

Scheme 1: Chemoenzymatic synthesis of enantioenriched enantiomers of promethazine 9 and ethopropazine 10. Reagents and conditions: (i) $n$-BuLi (1.5 equiv), dry THF, $1 \mathrm{~h}$ at $-78{ }^{\circ} \mathrm{C}$, then propylene oxide 2 (2 equiv), $12 \mathrm{~h}$ at rt; (ii) $\mathrm{CH}_{3} \mathrm{COCl}$ (1.5 equiv) or $\mathrm{C}_{3} \mathrm{H}_{7} \mathrm{COCl}\left(1.5\right.$ equiv) or $\mathrm{C}_{9} \mathrm{H}_{19} \mathrm{COCl}$ (1.5 equiv), $\mathrm{NEt}_{3}$ (1.5 equiv), DMAP ( 0.1 equiv), dry $\mathrm{CH}_{2} \mathrm{Cl}_{2}, 12 \mathrm{~h}$ at rt; (iii) vinyl ester (3 equiv), lipase [20\% (w/w)], MTBE, $25^{\circ} \mathrm{C}, 500 \mathrm{rpm}$ (magnetic stirrer); (iv) $\mathrm{NaOH}$ (1.1 equiv), $\mathrm{MeOH}, 1 \mathrm{~h}$ at rt; (v) $\mathrm{PBr}_{3}$ (1 equiv), $\mathrm{CH}_{2} \mathrm{Cl}_{2}, 2 \mathrm{~h}$ at rt; (vi) $\mathrm{Me}_{2} \mathrm{NH}$ ( 5 equiv) or $\mathrm{Et}_{2} \mathrm{NH}$ (20 equiv), $\mathrm{MeOH}$, sealed tube, $4 \mathrm{~d}$ at $90{ }^{\circ} \mathrm{C}$ (temperature of oil bath); (vii) $\mathrm{Me}_{2} \mathrm{NH}$ (25 equiv) or $\mathrm{Et}_{2} \mathrm{NH}$ (50 equiv), $\mathrm{PhCH}_{3}$, sealed tube, $7 \mathrm{~d}$ at $140{ }^{\circ} \mathrm{C}$ (temperature of oil bath). 
non-regioselective propylene oxide ring opening. With the hope of eliminating the unwanted side-product formation, we thereby performed the reaction under phase transfer catalysis (PTC) conditions. The results of this experiments have shown that independently from the type of the used reaction media (toluene, $\mathrm{CH}_{2} \mathrm{Cl}_{2}$, diethyl ether), bases $(50 \% \mathrm{NaOH}$ or $60 \%$ $\mathrm{KOH}$ ), and the applied PTC-catalysts [tetrabutylammonium bromide (TBAB) or tetrabutylammonium hydrogensulfate (TBAHS)], the epoxide 2 ring opening proceeded unsuccessfully. Again, the amount of the formed impurities was too large to isolate pure fraction. This provoked us to change the synthetic strategy by excluding at first propylene oxide (2) as the reagent. Reported in the literature various PTC-mediated alkylations of phenothiazine (1) with various alkyl and alkenyl halides [61-64], inspired us to prepare the 10-(prop-2-en-1-yl)-10Hphenothiazine derivative as potent substrate for the synthesis of $( \pm)$-3. This was smoothly achieved in high yield (76\%) by using allyl bromide in biphasic system composed of $\mathrm{CH}_{2} \mathrm{Cl}_{2} / 50 \%$ $\mathrm{NaOH}$ and the additive TBAHS as the catalyst at room temperature. The obtained 10-(prop-2-en-1-yl)-10H-phenothiazine was subsequently conducted into an oxymercuration-demercuration reaction accordingly to the procedure proposed by Abreu et al. [65]. Although the recorded mass spectra (HRMS-ESI) for the thus prepared product $( \pm)-\mathbf{3}$ showed the quasi-molecular peak corresponding to the calculated value, and both the gas chromatography (GC) as well as thin layer chromatography (TLC) showed a single peak and spot respectively, the signals of the measured ${ }^{1} \mathrm{H}$ NMR spectra were strongly diffused and could not be easily interpreted. This can be explained by the presence of traces of diamagnetic impurities $\left(\mathrm{Hg}^{2+}\right.$-complex $)$ in the sample of $( \pm)$-3, which caused severe broadening of the signals due to reduction of relaxation times. This prevents $( \pm)-3$ to be accomplished in the required purity for pharmaceuticals production. All other attempts performed by us, which concerned $N$-alkylation of 1 with various alkyl agents such as: 1-chloropropan-2ol, (1-chloropropan-2-yloxy)trimethylsilane or chloroacetone under PTC or NaH-base conditions, failed as well leading to complex mixtures. The above mentioned drawbacks were finally overcome by using the lithium salt of phenothiazine 1 for the oxirane 2 ring opening as it was described at the beginning of this paragraph.

To obtain racemic esters $( \pm)-\mathbf{4 a}-\mathbf{c}$ which are required for robust analytical HPLC separation studies of the corresponding pairs of enantiomers and for the measurement of the enantiomeric excess values of the compounds prepared in the biocatalyzed reactions, the afore-prepared alcohol $( \pm)-\mathbf{3}$ was reacted with the appropriate acyl chloride in dry dichloromethane in the presence of triethylamine and a catalytic amount of 4- $N, N$-dimethylaminopyridine (DMAP). This was leading to moderate yields $(41-68 \%)$ of the acetates.

\section{Lipase-catalyzed kinetic resolution of $( \pm)-\mathbf{3}$}

To address the challenges associated with the determination of the best reaction conditions for the asymmetric chemoenzymatic total synthesis of promethazine (9) and ethopropazine (10), necessary optimization studies of the lipase-catalyzed kinetic resolution of $( \pm)-3$ were undertaken. For that purpose, we considered the influence of major factors including: (i) type of the lipase, (ii) choice of the co-solvent, (iii) reaction time, and (iv) kind of acyl donor on the yield and enantioselectivity outcome of the overall process. For preliminary analysis, we followed the strategy of keeping all the other experimental parameters constant, i.e., stirring speed (500 rpm), enzyme loading in respect to substrate $(20 \% \mathrm{w} / \mathrm{w})$, substrate-to-acyl group donor molar ratio $(1: 30)$, and the temperature $\left(25^{\circ} \mathrm{C}\right)$. Finally, after finding optimal biotransformation conditions in a mg-scale, we have successfully performed the reaction in gram- and multigram-scales providing sufficient amounts of optically active alcohol intermediates $(S)-(+)-5$ and $(R)-(-)-7$ enabling to continue the planned synthesis. Each of the reaction parameters and up-scaling approaches are discussed in detail in the following paragraphs.

\section{Biocatalyst effect on the kinetic resolution of $( \pm)-3$}

The enzymatic kinetic resolution of $( \pm)$-3 was initially attempted using a representative set of 14 different lipases isolated from various microorganisms (see Supporting Information File 1 for details). Among the broad panel of investigated commercially available preparations, immobilized lipases of a fungal origin such as Novozym 435, Chirazyme L-2, C2, Chirazyme L-2, C3, and Lipozyme TL IM were established as optimal biocatalysts for the enantioselective transesterification when suspended in 30 equiv of vinyl acetate as the acyl donor, methyl tert-butyl ether (MTBE) as co-solvent, and carried out at $25{ }^{\circ} \mathrm{C}$, with agitation speed of the magnetic stirrer arranged at $500 \mathrm{rpm}$, and an enzyme loading of $20 \% \mathrm{w} / \mathrm{w}$ in respect to substrate $( \pm)-\mathbf{3}$.

Whereas preliminary experiments showed that four of the above-mentioned lipase preparations exhibited good enzymatic activities and excellent enantioselectivities towards racemic alcohol $( \pm)-3$, it would have been insufficient to select the most promising catalyst only on the basis of single random results obtained from the analysis of the reaction mixtures. By virtue of the importance of enzyme selection, and to find the most suitable catalyst for the transesterification of racemic alcohol $( \pm)-3$ as well as to provide better insight into the reaction progress of each of the chosen lipases in general, comprehensive kinetic studies were assessed (Figure 1). Effect of the reaction time on the conversion degree of phenothiazinic alcohol $( \pm)-\mathbf{3}$ and the overall progress of the followed enzymatic process was esti- 

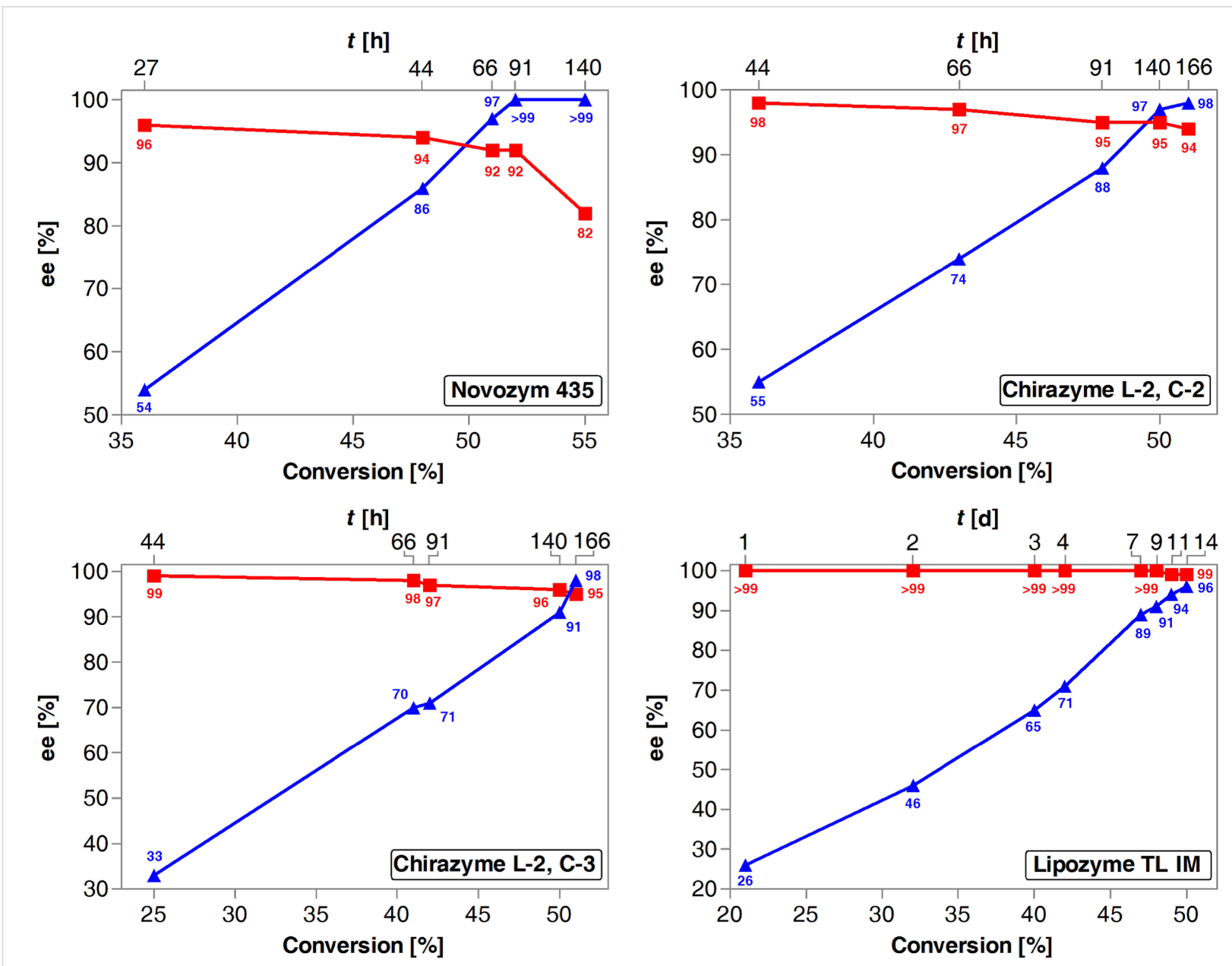

Figure 1: Dependence of optical purities (\% ee) of $(R)-(-)-6 a$ (red curve, $\boldsymbol{\square})$ and $(S)-(+)-5$ (blue curve, $\mathbf{\Delta})$ on the conversion degree of $( \pm)-3$ during lipase-catalyzed acetylation with vinyl acetate in a MTBE solution at $25^{\circ} \mathrm{C}$ (magnetic stirrer, at $500 \mathrm{rpm}$ ).

mated by high-performance liquid chromatography (HPLC) analysis using a Chiralcel OD-H column. The products could be analyzed directly from the crude mixture since the conditions of the HPLC chiral stationary phases were adjusted to the needs of both resolution products (peaks of the alcohol and the acetate enantiomers were well separated) (see the Supporting Information File 1 for details). The plots presented in Figure 1 clearly indicate that in terms of enantioselectivity, the best results were obtained with Lipozyme TL IM with an enantiomeric ratio factor $(E)$ reaching up to 790 for $49 \%$ conversion achieved after 14 days, whereas other lipase preparations generally displayed lower enantioselectivities (with $E$-values up to 180).

While tracing the course of the Lipozyme TL IM-catalyzed reaction it became evident that in most cases substrate $( \pm)$-3 was slowly but ultra-selectively converted into the corresponding acetate $(R)-(-)-6 \mathbf{a}$ obtained with excellent enantiomeric excess ( $>99 \%$ ee), while the remaining alcohol $(S)-(+)-5$ was recovered only with $96 \%$ ee due to the fact that the reaction defi- nitely stopped at $49 \%$ conversion being reached after two weeks. The specificity of this lipase for the $(R)$-alcohol was evident since even after such a long reaction time, no trace of the $(S)$-configured ester was detected. As occurred at elevated temperature $\left(35^{\circ} \mathrm{C}\right)$, the reaction did not proceed further with longer reaction times. Nevertheless, the results obtained with this lipase were truly impressive, as all the investigated samples revealed that generated ester $(R)-(-)-6 a$ was enantiomerically pure ( $>99 \%$ ee) regardless of the time and the conversion.

In turn, the reaction rate was considerably improved in Novozym 435-catalyzed analytical scale acetylation. This revealed that Candida antarctica lipase B (CAL-B) immobilized on acrylic resin was superior to other enzymes in both the reaction rate and the obtained enantiomeric excess values of the slower reacting enantiomer $(S)-(+)-5$. In this case, racemic alcohol $( \pm)$-3 has been successfully resolved affording the unreacted substrate $(S)-(+)-5$ in enantiopure form $(>99 \%$ ee), whereas the ester $(R)-(-)-6 a$ was yielded in high enantiomeric 
excess $(82-92 \%$ ee) when the reaction slightly exceeded $52 \%$ conversion. As can be seen in Figure 1, the time necessary to achieve the appropriate $51 \%$ conversion for Novozym 435 catalyzed reaction was diminished by 2.5 orders-of-magnitude when compared to both Chirazyme-type preparations. Even more significant (by 5 orders-of-magnitude) difference in the speed of the reactions was observed when comparing the time necessary for ca. $48 \%$ conversion achievement in the case of Novozym 435 and Lipozyme TL IM lipases. On the other hand, Chirazyme L-2, C2 and Chirazyme L-2, C3 displayed very high enantioselectivity $(E=149-180)$ yielding stereoselectively acetylated derivative $(R)-(-)-6 a$ in high enantiomeric excess (94-95\% ee) and unreacted alcohol $(S)-(+)-5$ with $98 \%$ ee. Examination of both reaction progresses showed very characteristic trends in kinetics for this type of lipase-catalyzed reaction, where an almost linear increase in the enantiomeric excess during the formation of optically active alcohol $(S)-(+)-5$ could be observed. However, although good selectivities were attained in the kinetic resolution of $( \pm)$-3 catalyzed by both Chirazyme preparations, the reaction rates were low and 51\% conversion was achieved after $166 \mathrm{~h}$ hampering the development of a straightforward route to optically active targeted pharmaceuticals 9 and 10. The afore-outlined results forced us to cease further optimization studies with these particular lipases. The enzyme selection stage leads to the conclusion that reactions catalyzed by Novozym 435 were beneficial for obtaining the alcohol $(S)-(+)-5$ in enantiopure form, while highly optically pure acetate $(R)-(-)-6$ a was obtained with Lipozyme TL IM as the catalyst. These findings provoked us to investigate the kinetic resolution of ( \pm )-3 by using both Novozym 435 and Lipozyme TL IM preparations in the next optimization stages.

\section{Solvent effect on kinetic resolution of $( \pm)-3$}

The next stage of enzymatic analytical scale studies was designed to find the most suitable co-solvent system for the enantioselective $O$-acylation of racemic alcohol $( \pm)$-3 using vinyl acetate. All experiments of the kinetic resolution of enantiomers $( \pm)-\mathbf{3}$ were conducted under the same reaction conditions as described above, using immobilized lipases: Novozym 435 and Lipozyme TL IM as the catalysts, respectively.

It is well-known that the nature of solvent could significantly influence the activity and selectivity of the enzymatic reaction as well as increase the thermal stability of enzymes [66]. The high sensitivity of lipases towards the medium environment mainly stems from experimental observations that different organic solvents had a different ability to interact with amino acid residues which are responsible for the catalytic activity. For example, it is well documented [67-69] that polar solvents $(\log P<1)$ are less suitable for biocatalytic purposes since hydrophilic media (such as methanol, ethanol, acetone, acetonitrile etc.) distort the active conformation of the enzyme molecule by destabilizing electrostatic interactions, and even strip off the essential water layer (water of hydration) leading to loss of the biocatalytic activity. In turn, more lipophilic organic solvents positively interact with the enzyme protein enhancing its secondary structure mainly by stabilization of the internal hydrogen-bonding network in the molecule, thus improving the reactivity and selectivity of organic substrate transformations.

Therefore, an appropriate medium selection in which a relatively high solubility of the phenothiazinic substrate $( \pm)-3$ as well as a good enzymatic activity and selectivity are retained, is being of particular significance for the overall success of the process. Five different apolar organic solvents (varying in $\log P$, dielectric constant $\varepsilon$, dipolar moment $\mu$ ) including: $n$-hexane, pentane, toluene, MTBE, and diethyl ether $\left(\mathrm{Et}_{2} \mathrm{O}\right)$ were investigated as the reaction media. Additionally, both lipase catalysts were also screened in neat vinyl acetate (Table 1). The courses of all the enzymatic reactions were monitored by gas chromatography (GC), arrested deliberately after 7 days, and only then their final evolution were subsequently followed by chiral HPLC.

As a first attempt, Novozym 435-catalyzed KR of racemic alcohol ( \pm )-3 was carried out (Table 1, entries 1-6). After series of experiments, the influence of various co-solvents could be summarized as the following row orders in terms of enzyme activity: pentane $>n$-hexane $\approx \mathrm{MTBE} \approx \mathrm{Et}_{2} \mathrm{O}>$ toluene $\approx$ vinyl acetate, and the reaction enantioselectivity: toluene $>$ vinyl acetate $>n$-hexane $>$ MTBE $\approx \mathrm{Et}_{2} \mathrm{O}>$ pentane. As it was observed, the acetylation reaction in toluene was mostly enantioselective $(E=180)$, thus transforming the racemic starting material $( \pm)-\mathbf{3}$ into optically active ester $(R)-(-)-6 \mathbf{a}$ of high enantiomeric excess ( $95 \%$ ee) and leaving thereby slower reacting enantiomer $(S)-(+)-5$ of very high enantiomeric purity ( $98 \%$ ee). On the other hand, from the view point of remaining the enatiopurity of alcohol $(S)-(+)-5$, ethereal solvents $\left(\mathrm{Et}_{2} \mathrm{O}\right.$ and MTBE) which yielded $(S)-(+)-5$ with excellent enantiomeric excess ( $>99 \%$ ee) are even better. It is obvious that since methyl tert-butyl ether is free from dangerous peroxides, hence it was chosen for further optimization studies concerning Novozym 435 lipase.

In turn, while investigating the acylation of $( \pm)-3$ catalyzed by Lipozyme TL IM suspended in chosen co-solvents systems (Table 1, entries 7-12) we noticed the following row order of the reaction velocity: $\mathrm{MTBE}>$ pentane $>\mathrm{Et}_{2} \mathrm{O}>$ toluene $>$ vinyl acetate $>n$-hexane. Quite surprisingly, the same order was observed for the reaction enantioselectivity. As can be seen, among the investigated apolar solvents for Lipozyme TL IM- 
Table 1: Solvent influence on the selective O-acetylation of ( \pm )-3 in the presence of lipase preparation (Novozym 435 or Lipozyme TL IM) with vinyl acetate in MTBE at $25^{\circ} \mathrm{C}$ after 7 days.

\begin{tabular}{|c|c|c|c|c|c|c|}
\hline Entry & Enzyme $^{a}$ & Solvent $(\log P)^{\mathrm{b}}$ & conv. ${ }^{c}(\%)$ & $e_{s}^{d}(\%)$ & $e_{p}^{d}(\%)$ & $E^{e}$ \\
\hline 1 & Novozym 435 & hexane (3.00) & 53 & $>99$ & 89 & 90 \\
\hline 2 & & pentane (2.58) & 54 & $>99$ & 84 & 59 \\
\hline 3 & & toluene (2.52) & 51 & 98 & 95 & 180 \\
\hline 4 & & MTBE (0.96) & 53 & $>99$ & 88 & 82 \\
\hline 5 & & $\mathrm{Et}_{2} \mathrm{O}(0.76)$ & 53 & $>99$ & 88 & 82 \\
\hline 6 & & vinyl acetate $(0.54)$ & 51 & 97 & 94 & 136 \\
\hline 7 & Lipozyme TL IM & hexane (3.00) & 18 & 22 & 98 & 123 \\
\hline 8 & & pentane (2.58) & 41 & 70 & $>99$ & 419 \\
\hline 9 & & toluene (2.52) & 29 & 40 & 99 & 295 \\
\hline 10 & & MTBE (0.96) & 44 & 78 & $>99$ & 474 \\
\hline 11 & & $\mathrm{Et}_{2} \mathrm{O}(0.76)$ & 37 & 58 & $>99$ & 359 \\
\hline 12 & & vinyl acetate $(0.54)$ & 28 & 39 & 99 & 292 \\
\hline
\end{tabular}

aConditions: ( \pm )-3 $100 \mathrm{mg}$, lipase $20 \mathrm{mg}$, organic solvent $1 \mathrm{~mL}$, vinyl acetate $948 \mathrm{mg}\left(1 \mathrm{~mL}, 28\right.$ equiv), $25^{\circ} \mathrm{C}, 500 \mathrm{rpm}$ (magnetic stirrer). ${ }^{\mathrm{b}} \mathrm{Logarithm}$ of the partition coefficient of a given solvent between $n$-octanol and water according to ChemBioDraw Ultra 13.0 software indications. ${ }^{\mathrm{C} B a s e d}$ on GC, for confirmation the $\%$ conversion was calculated from the enantiomeric excess of the unreacted alcohol (ee $\left.{ }_{s}\right)$ and the product $\left(e e_{p}\right)$ according to the formula conv. $=\mathrm{ee}_{\mathrm{s}} /\left(\mathrm{ee}_{\mathrm{s}}+\mathrm{ee}_{\mathrm{p}}\right) \cdot{ }^{\mathrm{d}}$ Determined by chiral HPLC analysis by using a Chiralcel OD-H column. ${ }^{\mathrm{e} C a l c u l a t e d}$ according to Chen et al. [70], using the equation: $E=\left\{\ln \left[(1-\right.\right.$ conv. $\left.\left.)\left(1-e_{s}\right)\right]\right\} /\left\{\ln \left[(1-\right.\right.$ conv. $\left.\left.)\left(1+e_{s}\right)\right]\right\}$.

catalyzed kinetic resolution of $( \pm)-3$, the best results were achieved in MTBE both in terms of enzyme activity and reaction enantioselectivity.

\section{The effect of the acyl donor on the kinetic resolution of $( \pm)-3$}

A considerable number of fundamental researches have been performed to explain the influence of the acyl group donor type on the lipase-catalyzed acylation of alcohols. Amongst the wide range of this reagent type, enol esters (i.e., vinyl acetate, isopropenyl acetate), activated esters (i.e., trifluoroethyl butyrate, $S$-ethyl thiooctanoate), non-activated esters (i.e., ethyl acetate, methyl acetate), and anhydrides (i.e., acetic acid anhydride, succinic acid anhydride) are most commonly used. Unfortunately, there are several drawbacks of incorporating the above-mentioned reagents into transesterification processes, i.e., trifluoroethyl esters are very expensive, $S$-ethyl thioesters generate undesirable flavor of the formed thiols, employment of anhydrides yields free carboxylic acids causing enzyme deactivation, and finally application of conventional esters, despite their great availability and low price, could reverse acylation into alcoholysis due to alcohol formation during the course of reaction. Of course, removal of alcohol from the reaction system by, i.e., $4 \AA$ molecular sieves could prevent lipasecatalyzed alcoholysis of the formed ester and thus shift the reaction toward the product. However, a straightforward method to avoid the formation of alcohol molecules is available, and assumes the use of vinyl esters as the acyl group donors. Moreover, from the application point of view, vinyl esters are significantly practical reagents since in situ generated unstable vinyl alcohol instantly and irreversibly tautomerizes to acetaldehyde, thus shifting the state of equilibrium in product direction. Therefore, in next experiments three different vinyl esters were used: vinyl acetate, vinyl butanoate, and vinyl decanoate. The influence of the acyl donor nature on the course of the alcohol acylation reaction was examined using 3 equiv of the appropriate vinyl ester under catalysis of the corresponding lipase (Novozym 435 or Lipozyme TL IM) suspended in MTBE as solvent, and stirred at $25{ }^{\circ} \mathrm{C}$ using a magnetic stirrer. All the assays were regularly traced by HPLC analyses after 1, 2, 4 and 7 days, respectively (Table 2). Consideration of the results summarized in Table 2 leads to the conclusion that the highest enantioselectivity $(E=844)$ of the reaction has been observed in the acylation of racemic alcohol $( \pm)-\mathbf{3}$ in the presence of Lipozyme TL IM, and vinyl acetate as an acyl transfer reagent. In accordance with the previous experiments, this extremely enantioselective lipase preparation afforded recovery of ester $(R)-(-)-6$ a with perfect optical purity ( $>99 \%$ ee) at a conversion in the rage of $39-49 \%$ (Table 2, entries 4-7). On the other hand, since the Lipozyme TL IM-catalyzed acetylation tends to cease before achieving 50\% conversion, the remaining alcohol $(S)-(+)-5$ could be obtained only with a moderate enantiomeric excess (63-97\% ee) reaching the highest optical purity $(97 \%$ ee) after 7 days (Table 2, entry 7). In turn, KR of ( \pm )-3 conducted with vinyl acetate in the presence of Novozym 435 showed that after $24 \mathrm{~h}$ the enantiomeric purity of $(S)-(+)-5$ increased over $77 \%$ ee and reached the $98 \%$ ee after $48 \mathrm{~h}$ (Table 2, entry 1). Complete optical purification ( $>99 \%$ ee) of the remaining alcohol $(S)-(+)-5$ was observed after a reaction time of 4 days (Table 2, entry 4 ). As can be also seen from data 
Table 2: The influence of various acyl donors (3 equiv) upon the selectivity of Novozym 435 and Lipozyme TL IM for the O-acetylation of ( \pm )-3 in MTBE at $25^{\circ} \mathrm{C}$

\begin{tabular}{|c|c|c|c|c|c|c|c|}
\hline Entry & Enzyme $^{a}$ & Acyl donor & $t(\mathrm{~d})$ & conv. ${ }^{b}(\%)$ & $\mathrm{ee}_{\mathrm{s}}^{\mathrm{c}}(\%)$ & $e_{p}^{c}(\%)$ & $E^{\mathrm{d}}$ \\
\hline 1 & Novozym 435 & vinyl acetate & 1 & 44 & 77 & 98 & 232 \\
\hline 2 & & & 2 & 51 & 98 & 91 & 97 \\
\hline 3 & & & 4 & 52 & $>99$ & 90 & 99 \\
\hline 4 & Lipozyme TL IM & & 1 & 39 & 63 & $>99$ & 382 \\
\hline 5 & & & 2 & 45 & 80 & $>99$ & 492 \\
\hline 6 & & & 4 & 48 & 91 & $>99$ & 637 \\
\hline 7 & & & 7 & 49 & 97 & $>99$ & 844 \\
\hline 8 & Novozym 435 & vinyl butanoate & 1 & 51 & $>99$ & 94 & 170 \\
\hline 9 & & & 2 & 53 & $>99$ & 88 & 82 \\
\hline 10 & & & 4 & 57 & $>99$ & 76 & 37 \\
\hline 11 & Lipozyme TL IM & & 1 & 49 & 95 & $>99$ & 747 \\
\hline 12 & & & 2 & 50 & $>99$ & 98 & 525 \\
\hline 13 & & & 4 & 51 & $>99$ & 94 & 170 \\
\hline 14 & Novozym 435 & vinyl decanoate & 1 & 48 & 91 & 98 & 317 \\
\hline 15 & & & 2 & 49 & $>99$ & 94 & 713 \\
\hline 16 & & & 4 & 52 & $>99$ & 91 & 111 \\
\hline 17 & Lipozyme TL IM & & 1 & 48 & 93 & 99 & 684 \\
\hline 18 & & & 2 & 50 & $>99$ & 98 & 525 \\
\hline 19 & & & 4 & 50 & $>99$ & 98 & 525 \\
\hline
\end{tabular}

aConditions: ( \pm )-3 $100 \mathrm{mg}$, lipase $20 \mathrm{mg}$, MTBE $2 \mathrm{~mL}$, vinyl ester (3 equiv), $25^{\circ} \mathrm{C}, 500 \mathrm{rpm}$ (magnetic stirrer). ${ }^{\mathrm{b}, \mathrm{c}, \mathrm{d}}$ See notes ${ }^{\mathrm{c}, \mathrm{d}}$ and ${ }^{\mathrm{e}}$ above (Table 1).

presented in Table 2, both the rate and enantioselectivity of the enzymatic reactions could be significantly improved by using fatty acid vinyl esters. After analyzing the effect of those acyl group donors general findings can be presented: (i) $(S)-(+)-5$ alcohol with excellent enantiomeric excess $(>99 \%$ ee) could be obtained after a relatively short time of $24 \mathrm{~h}$ when vinyl butanoate was used, and the reaction was catalyzed by Novozym 435 (Table 2, entry 8); (ii) in turn, the highest enantiopurity of the formed $(R)$-enantiomer could be attained in the enzymatic transesterification proceeded with Lipozyme TL IM and vinyl butanoate as an acyl donor, appropriately arrested after $24 \mathrm{~h}$, while $49 \%$ conversion was reached (Table 2, entry 11); (iii) another characteristic tendency was observed in the case of the velocity of Novozym 435-catalyzed reactions, in which the influence of the acyl group donor was pronounced more markedly than in the case of Lipozyme TL IM. For example, when the reaction was carried out with vinyl butanoate, Novozym 435 allowed $51 \%$ conversion to be achieved after remarkably 4 -fold shorter reaction time compared with those conducted with vinyl acetate and vinyl decanoate (Table 2, Entry 8 vs 3 and 16), respectively.

As a conclusion, the enantioselectivity and rate of lipasecatalyzed KR of $( \pm)-\mathbf{3}$ in MTBE were significantly affected by the nature of an acyl transfer reagent, thus allowing the excel- lent enantiomer separation with 3 equiv of vinyl butanoate (Table 2, entries 11 and 12). However, enzymatic kinetic resolution with $E=747$ has to be stopped at ca. $49 \%$ conversion in order to obtain $(R)-(-)-6 \mathbf{b}$ in fully enantiopure form ( $>99 \%$ ee), and somewhat over $50 \%$ conversion in order to acquire the unreacted $(S)-(+)-5$ at $>99 \%$ ee and superb enantioselectivity $(E=525)$. This observation hints that careful monitoring of the reaction and its appropriate termination allows to receive both resolution products $(S)-(+)-\mathbf{5}$ and $(R)-(-)-\mathbf{6 b}$ or $(R)-(-)-\mathbf{6 c}$ with very high enantiopurity $(98-100 \%$ ee) what may facilitate preparatory-scale synthesis. However, taking into account the clear advantages of vinyl acetate such as (i) the relatively high volatility (hence possibility of easy recovery of the product and remaining substrate), and (ii) lower cost when compared to the employed long-chain fatty acid vinyl esters, as well as the fact that (iii) vinyl acetate displayed acceptable impact on the performance of the lipases, we reasoned to set it as the reagent of choice for further up-scaling investigations using both heretofore examined enzymes.

\section{Preparative-scale lipase-catalyzed kinetic resolution of $( \pm)-3$}

An optimized protocol for obtaining enantiopure key intermediates $(S)-(+)-5$ and $(R)-(-)-6 a-c$ on a milligram-scale $(100 \mathrm{mg})$ was successfully achieved. In order to provide further insight 
into enzymatic kinetic resolution of $( \pm)$-3 enantiomers, and to show its potential as a method for asymmetric synthesis of enantiomerically pure pharmaceuticals 9 and 10, this part of our study was aimed for investigating the feasibility of proceeding the enantioselective transesterification on a significantly larger scale. Bearing in mind that the fortune of this issue is critical for the development of a highly economic process at industrial scale, we decided to examine respective 10-fold, 20 -fold and 30 -fold linear enlargement of all the previously set parameters including the reagents concentrations, enzyme quantities and solvent volume under the optimized reaction conditions. Table 3 demonstrates the data of the lipase-catalyzed asymmetric $O$-acetylation of $( \pm)-3$ in one-, two-, and three-gramscale regarding their final effect on the total stereochemical outcome for the employed lipase preparations. We were pleased to see that the results were almost the same, regardless of the scale with, i.e., approx. $51 \%$ conversion after 4 days for the Novozym 435-mediated KR of racemic alcohol ( \pm )-3 (Table 2, entry 1 vs Table 3 , entry 1$)$. The kinetic resolution in the presence of this enzyme provided slower reacting enantiomer $(S)-(+)-5$ with perfect optical purity ( $>99 \%$ ee), and its acetylated counterpart $(R)-(-)-6 \mathbf{a}$ in enantioenriched form $(94 \%$ ee). The separation of the resolution products on a silica gel column chromatography revealed that the unreacted alcohol $(S)-(+)-5$ and the formed acetate $(R)-(-)-6$ a could be prepared with isolated yield in the range of $81-95 \%$, corresponding closely to the theoretical $50 \%$ proportions of the enantiomers in the racemate. Subsequent scaling of the reaction up to 2 and then up to 3 grams of the substrate $( \pm)-\mathbf{3}$ gave almost the same isolated yields of recovered alcohol $(S)-(+)-5$ and the acetate $(R)-(-)-6 \mathbf{a}$ with moderate to excellent enantiomeric excess for both compounds (69-100\% ee) (Table 3, entries 2 and 3), respectively. Again, a very similar chirality inducement occurred under Lipozyme TL IM- catalyzed conditions. In this manner, acetate $(R)-(-)-6 a$ was isolated chromatographically in $67 \%$ yield and excellent enantiomeric excess $(>99 \%)$ reached when the reaction was arrested at $46 \%$ conversion after 3 days (Table 3 , entry 4). From the same reaction mixture unreacted $(S)-(+)-5$ was isolated with $84 \%$ ee. Independent experiment conducted with this lipase using $3 \mathrm{~g}$ of starting material (Table 3, entry 5) closely matched the above mentioned results showing that this approach effected the resolution of $( \pm)-\mathbf{3}$ into $(S)-(+)-5$ alcohol $(99 \%$ ee) and $(R)-(-)-6 a$ ester $(86 \%$ ee) with a conversion value of $46 \%$ after 3 days. In the light of these findings, it became clear that this process proved to be flexible enough for being up-scaled in a straightforward manner. The amount of both enantiomers $(S)-(+)-5$ and $(R)-(-)-7$ obtained in the devised lipase-catalyzed resolution of $( \pm)-\mathbf{3}$ can be considered to be "in preparative scale" and ready-to-use for further transformations.

\section{Determination of the stereochemistry of alcohol (+)-5}

The determination of the absolute configuration is crucial for all chiral molecules, but it is especially important for active pharmaceutical ingredients (APIs) like those presented herein, whereas only one enantiomer has a high positive pharmaceutical effect, while its counterpart is significantly less active. The assignment of stereochemistry of one of the kinetically resolved products on this stage could not only serve the information about the catalytic behavior of the enzymes but also could help us to plan further steps of the synthesis. Therefore, the stereopreference of the above-studied lipase preparations was evaluated by means of modified Mosher's methodology described by Riguera et al. [71] In this relatively simple and widely-used experimental approach, the absolute configuration of the chiral substrate of unknown stereochemistry [in this case slower reacting alcohol $(+)-5$ with an absolute enantiomeric purity $(>99 \%$ ee)] was assigned by its independent reaction with the two enantiomers of an appropriate chiral derivatizing agent (CDA) followed by comparison of the ${ }^{1} \mathrm{H}$ NMR spectra of the

Table 3: Gram-scale enantioselective O-acetylation of $( \pm)-3$ under kinetically controlled conditions with vinyl acetate in MTBE at $25^{\circ} \mathrm{C}$.

\begin{tabular}{|c|c|c|c|c|c|c|}
\hline Entry & Enzyme & $t(\mathrm{~d})$ & conv. ${ }^{a}(\%)$ & $\mathrm{ee}_{\mathrm{s}}^{\mathrm{b}}(\%) /$ Yield $^{\mathrm{c}}(\%) /[\alpha]_{D}{ }^{\mathrm{d}}$ & $e_{p}^{b}(\%) /$ Yield $^{c}(\%) /[\alpha]_{D}^{d}$ & $E^{\mathrm{e}}$ \\
\hline 1 & Novozym $435^{f}$ & 4 & 51 & $>99 / 95 /+39.78$ (c 1.02) & $94 / 81 /-8.75$ (c 1.03) & 170 \\
\hline 2 & Novozym $435^{9}$ & 3 & 57 & $>99 / 83 /+35.00$ (c 1.10) & $75 / 86 /-7.43$ (c 1.01) & 50 \\
\hline 3 & Novozym $435^{\mathrm{h}}$ & 4 & 59 & >99/86/N.D. ${ }^{i}$ & 69/N.D.i/N.D.i & 27 \\
\hline 4 & Lipozyme TL IMf & 3 & 46 & $84 / 72 /+31.88$ (c 1.49) & $>99 / 67 /-8.30$ (c 1.44) & 532 \\
\hline 5 & Lipozyme TL IM ${ }^{\mathrm{h}}$ & 3 & 46 & $86 / 94 /+29.56$ (c 1.01) & $99 / 92 /-8.29$ (c 0.91) & 556 \\
\hline
\end{tabular}

aThe $\%$ conversion was calculated from the enantiomeric excess of the unreacted alcohol $\left(e_{\mathrm{s}}\right.$ ) and the product (ee $\mathrm{p}_{\mathrm{p}}$ ) according to the formula conv. $=e_{s} /\left(e_{s}+e e_{p}\right)$. ${ }^{b}$ Determined by chiral HPLC analysis by using a Chiralcel OD-H column. CIsolated yield after column chromatography (calculated on the basis of the theoretical number of moles arising from conversion rate, relative to theoretical amount, i.e., when $50 \%$ conversion is reached, up to the half of the acetate could be obtained). ${ }^{d}$ Specific rotation, $c$ solution in methylene chloride, $T=22-23^{\circ} \mathrm{C}$, respectively (see Supporting Information File 1 for details). ${ }^{e}$ Calculated according to Chen et al. [70], using the equation: $E=\{\ln [(1-\operatorname{conv}$. $)(1-\mathrm{ee})]\} /\{\ln [(1-\operatorname{conv}$. $)(1+$ $\left.\left.\left.\mathrm{ee}_{\mathrm{s}}\right)\right]\right\}$. ${ }^{\mathrm{f} C o n d i t i o n s: ~}( \pm)-31 \mathrm{~g}$, lipase $0.2 \mathrm{~g}$, MTBE $10 \mathrm{~mL}$, vinyl acetate $1 \mathrm{~g}$ (3 equiv), $25^{\circ} \mathrm{C}, 500 \mathrm{rpm}$ (magnetic stirrer). ${ }^{\mathrm{g} C o n d i t i o n s: ~(~} \pm$ )-3 $2 \mathrm{~g}$, lipase $0.4 \mathrm{~g}$, MTBE $20 \mathrm{~mL}$, vinyl acetate $2 \mathrm{~g}$ (3 equiv), $25^{\circ} \mathrm{C}, 500 \mathrm{rpm}$ (magnetic stirrer). hConditions: ( \pm ) $-33 \mathrm{~g}$, lipase $0.6 \mathrm{~g}, \mathrm{MTBE} 30 \mathrm{~mL}$, vinyl acetate $3 \mathrm{~g}$ (3 equiv), $25^{\circ} \mathrm{C}, 500 \mathrm{rpm}$ (magnetic stirrer). 'Not detected. 
two diastereomeric derivatives obtained (11 and 12, Scheme 2). As already exemplified by us in few other reports [72-75], the modified Mosher's methodology is easy to carry out and to interpret, and can be successively applied toward secondary alcohols with various heterocyclic substituents with a minimum of experimental work being invested as long as reliable CDA is employed. In all of our previous studies $\alpha$-methoxy- $\alpha$-phenylacetic acid ( $O$-methylmandelic acid, MPA) used in both enantiomeric forms turned out to be an excellent chiral auxiliary reagent for this type of derivatized compounds since it has given diastereomeric esters that were distinguishable by NMR spectroscopy with reasonable levels of accuracy in terms of determination of stereochemistry (Scheme 2).

Subsequently, the chemical shifts of the substituents directly bonded to the stereogenic centre of the investigated alcohol $(+)-5\left(\mathrm{~L}_{1} / \mathrm{L}_{2}\right)$ were compared, and their spatial location (absolute configuration) was determined in accordance with the signs of their differences $\left(\Delta \delta^{R S} \mathrm{~L}_{1}\right.$ and $\left.\Delta \delta^{R S} \mathrm{~L}_{2}\right)$ in both prepared MPA-derivatives 11 and 12 (Figure 2).

The chirality of asymmetric carbon in the alcohol ( + )- $\mathbf{5}$ could be established due to the following facts: (i) It has been empirically confirmed by Latypov et al. [76] (as a result of dynamic NMR studies) that a final prevalent conformation in the CDA- substrate system in the case of MPA esters of secondary alcohols renders the $s p$ rotamer, in which the methoxy group, the $\mathrm{C} \alpha$ carbon, and the carbonyl group of the MPA unit as well as the methine proton $(\mathrm{CH})$ of the alcohol moiety [the substrate $(+)-5$ part] are all situated in the same plane, whereas the phenyl ring is ca. perpendicular to the $\mathrm{C}=\mathrm{O}$ bond and coplanar with the $\mathrm{C}_{\alpha} \mathrm{H}$ bond. Both the methoxy and the carbonyl group are in a synperiplanar disposition (see Newman projections of the appropriate $(1 R, 2 S)$ - and $(1 S, 2 S)$-conformations in diastereomers 11 and 12 depicted in Figure 3). (ii) The main induced anisotropic magnetic field effect (shielding), which is generated by means of high $\pi$ electron density (present in the phenyl ring of the chiral auxiliary regent MPA), showed appropriate strength (intensity) giving rise to perceptible shifts in the ${ }^{1} \mathrm{H}$ NMR signals of the $\mathrm{L}_{1} / \mathrm{L}_{2}$ groups located close to the chiral carbon in each of the investigated derivatives 11 and 12. (iii) The ${ }^{1} \mathrm{H}$ NMR signals of the chiral MPA shift reagent did not overlap with those of the examined alcohol (+)-5 thus allowing easy interpretation of the recorded spectra.

Comparing the recorded ${ }^{1} \mathrm{H}$ NMR spectra of both CDAs derivatives 11 and 12 illustrated in Figure 3, the most remarkable features should be outlined as follows. The ${ }^{1} \mathrm{H}$ NMR data of $(R)$-MPA ester 11 show a general shielding effect as a consequence of the close proximity of the phenyl group, with impor-

\footnotetext{
Scheme 2: Assignment of the stereochemistry of enantiopure alcohol (+)-5 resulting from derivatization with $(R)$ - and (S)-MPA 11 and 12, respective-
ly.
}

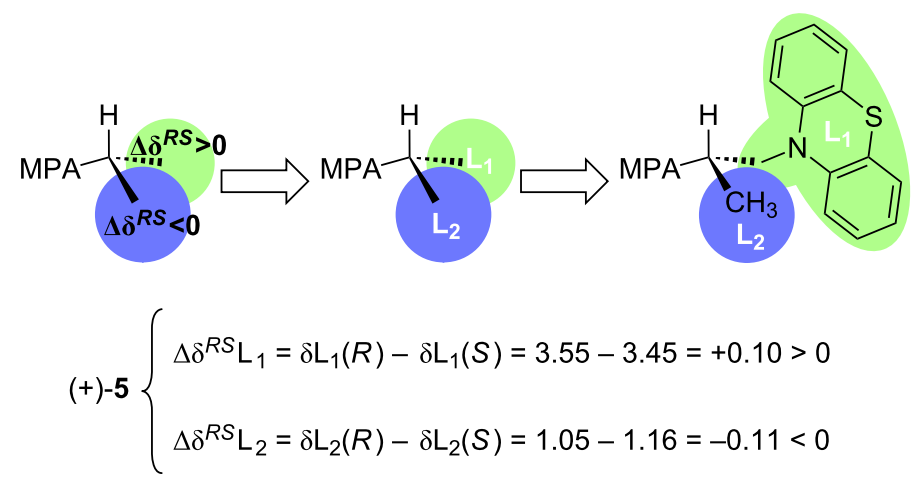

Figure 2: Description of substituents for determination of the absolute configuration of $(+)-5$ and $\Delta \delta^{R S}$ values obtained for the MPA esters 11 and 12. 

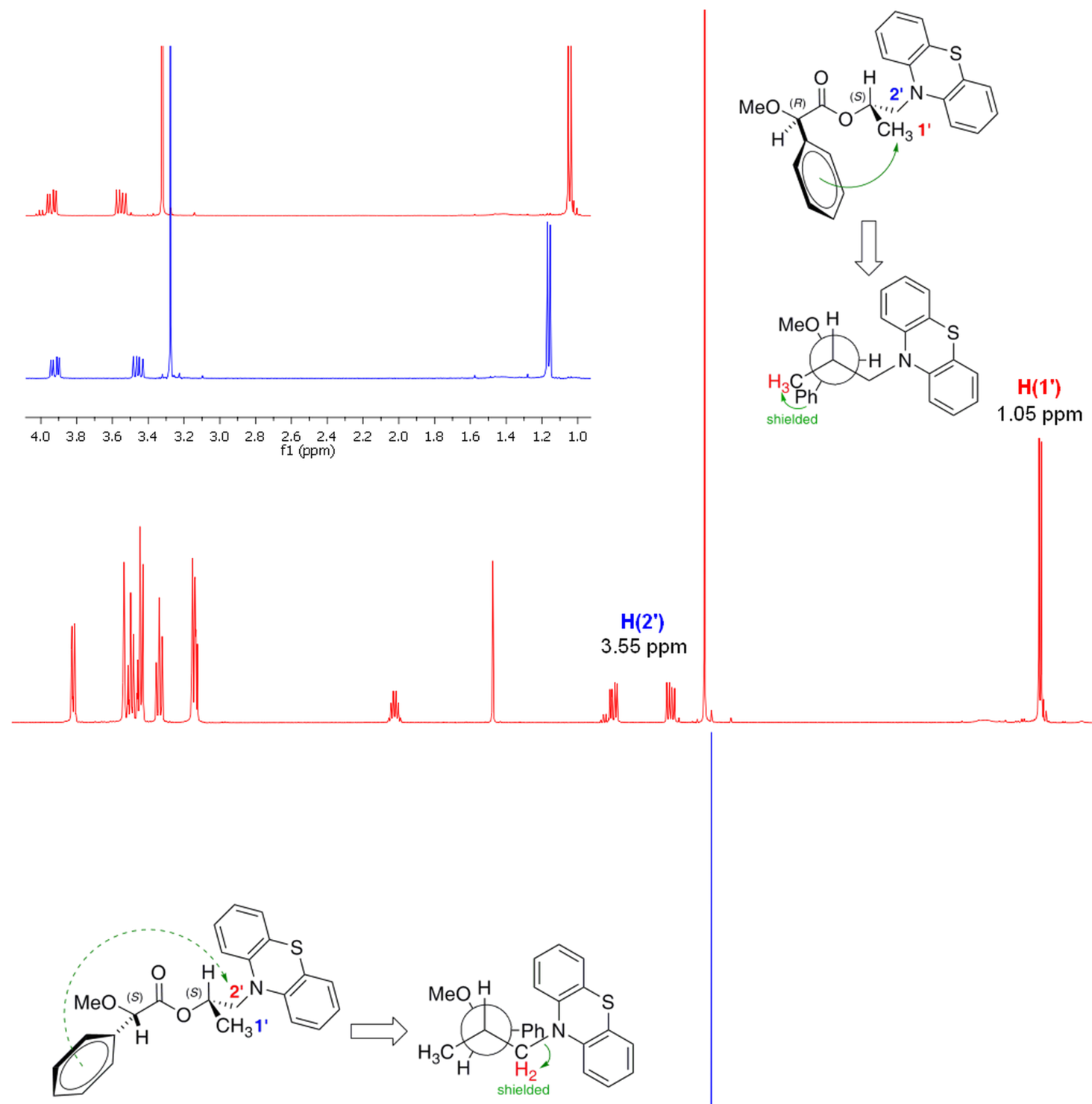

$H\left(2^{\prime}\right)$

$.55 \mathrm{ppm}$

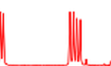

$\mathrm{H}\left(1^{\prime}\right)$

$1.16 \mathrm{ppm}$

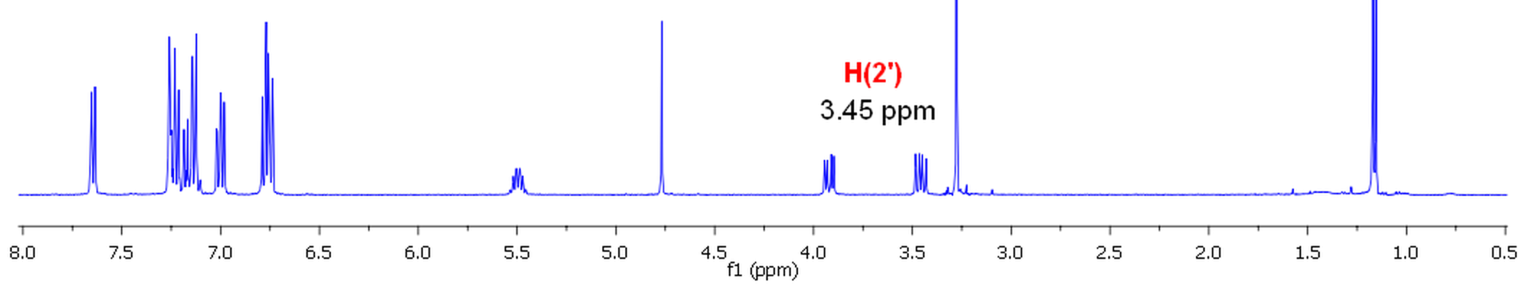

Figure 3: ${ }^{1} \mathrm{H} \mathrm{NMR}\left(\mathrm{CDCl}_{3}, 400 \mathrm{MHz}\right)$ spectra of the (R)-MPA 11 (red colored line) and (S)-MPA and 12 (blue colored line) derivatives of enantiopure alcohol $(+)-5(>99 \%$ ee). Additionally, with red color are marked protons shielded by the phenyl ring of chiral auxiliary, blue labels stand for unaffected protons. Green arrows indicate the shielding effect caused by the aromatic system. 
tant upfield shifts (lower frequency) for the signals assigned to $\mathrm{H}(1$ ') hydrogen atoms.

In turn, this particular $\mathrm{H}\left(1^{\prime}\right)$ signals in the spectrum for $(S)$ MPA derivative $\mathbf{1 2}$ are observed as unaffected and thus a downfield shift of the resonance signal occurs. The opposite phenomenon can be noticed when the protons of the methylene group $\mathrm{H}\left(2^{\prime}\right)$ in both MPA esters $\mathbf{1 1}$ and $\mathbf{1 2}$ are taken into account. In this situation, the $\mathrm{H}\left(2^{\prime}\right)$ protons of $(S)$-MPA derivative $\mathbf{1 2}$ are located under the shielding cone of the phenyl ring, which resulted in an upfield shift of the ${ }^{1} \mathrm{H}$ NMR signals in comparison to the signals from the (R)-MPA derivative $\mathbf{1 1}$.

The recognition of the absolute configuration of $(+)-5$ clearly indicates that both Novozym 435 and Lipozyme TL IM lipases follow Kazlauskas' rule [77], according to which the $(R)$-enantiomer of the chiral substrate $( \pm)-\mathbf{3}$ is preferentially acetylated.

In order to unambiguously confirm the adequacy of ${ }^{1} \mathrm{H}$ NMR shift analysis, the single crystal of enantiomerically pure alcohol (+)-5 ( $>99 \%$ ee) was subsequently analyzed by X-ray diffraction (XRD) method (Figure 4), which confirmed (S)-configuration and allowed us to conclude that Mosher's methodology can serve as a reliable determination method of the absolute configuration toward this type of compounds. For details concerning crystallization procedure and XRD measurements see Supporting Information File 1.

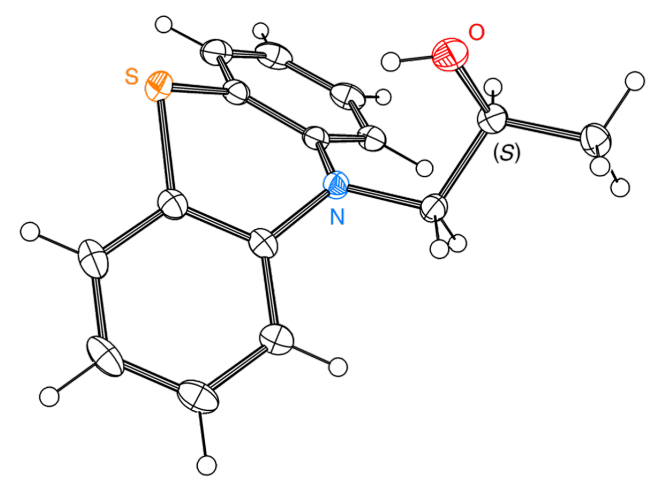

Figure 4: An ORTEP plot of $(S)-(+)-1-(10 H$-phenothiazin-10-yl)propan2-ol (S)-(+)-5. The following crystal structure has been deposited at the Cambridge Crystallographic Data Centre and allocated the deposition number CCDC-1018655.

\section{Approaches to the preparation of both enan- tiomeric forms of $\mathbf{9}$ and $\mathbf{1 0}$}

Although, the remaining synthesis of the final products $\mathbf{9}$ and $\mathbf{1 0}$ appears deceptively straightforward, it actually turned out to be a considerable challenge as the inversion of the chiral center in the intermediate molecules $\mathbf{3}$ and $\mathbf{8}$ has been identified as a key step in optimizing the process to avoid racemization. To save one step less, we initiated our efforts by direct transformation of the sec-alcohol functionality in afore-obtained compound ( \pm )-3 under modified Mitsunobu [78,79] reaction conditions using $\mathrm{Ph}_{3} \mathrm{P}$ (1.1 equiv), DEAD (1.1 equiv), and the respective amine ( 1 equiv of $\mathrm{Et}_{2} \mathrm{NH}$ or $\mathrm{Me}_{2} \mathrm{NH}$ ) conducted in dry THF. Since the Mitsunobu condensation protocol is considered as particularly attractive due to the superior reactivity of the in situ-generated corresponding oxyphosphonium intermediate on nucleophilic substitution, we envisioned that in this scenario the hydroxy moiety would be inverted under mild reaction conditions and in a desired one-pot stereospecific manner. To validate this hypothesis, the reaction was at first performed using model racemic alcohol $( \pm)-3$, and in two variants of reagents addition order. To our disappointment, none of these attempts led to success. When Mitsunobu chemistry fails, a hydroxy group inversion by tosylation and displacement using amine was performed. Unfortunately, attempts to carry out the reaction at higher temperature led to complete decomposition of the tosylate substrate. In the forward direction to synthesize optically active pharmaceuticals 9 and 10, we decided to prepare both enantiomers of corresponding bromide derivative $\mathbf{8}$. This was obtained by treatment of afore-prepared enantiopure alcohol $(S)-(+)-5$ with 1 equiv of phosphorus tribromide $\left(\mathrm{PBr}_{3}\right)$ at room temperature carried out for $2 \mathrm{~h}$. This allows to access $(R)-(+)-8$ in $>99 \%$ ee and in $27 \%$ yield. In turn, to afford its bromide counterpart $(S)-(-)-8$ a two-step reaction sequence has to be performed. At first, optically active acetate $(R)-(-)$-6a was transformed into the corresponding alcohol $(R)-(-)-7$ through simple cleavage of the acetyl group by means of $\mathrm{NaOH}-$ mediated mathanolysis. This resulted in the formation of $(R)-(-)-7$ in high $76 \%$ yield and almost without loss of the optical purity (98\% ee). Secondly, thus-obtained $(R)-(-)-7$ was converted to $(S)-(-)-8$, but surprisingly with partial loss in enantiomeric excess $(96 \%$ ee) despite using the same procedure as for the reaction between $(S)-(+)-5$ and $\mathrm{PBr}_{3}$. In addition, bromination of $(S)-(+)-5$ under Appel reaction conditions employing tetrabromomethane $\left(\mathrm{CBr}_{4}\right)$ as a halide ion source used along with triphenylphosphine $\left(\mathrm{Ph}_{3} \mathrm{P}\right)$ was also investigated. Although this approach proceeded to give $(R)-(+)-8$ in considerably higher yield $(77 \%)$, the obtained result was inferior from the stereochemical point of view as the reaction was non-selective and led to afford $(R)-(+)-8$ of poor $23 \%$ ee. With both enantiomers of bromo derivative $(R)-(+)-8$ and $(S)-(-)-8$ in hand, we have subsequently proceeded amination with $\mathrm{Et}_{2} \mathrm{NH}$ and $\mathrm{Me}_{2} \mathrm{NH}$, respectively. In all cases, a sealed glass vessel was used since these reactions need to be operated mostly at elevated temperatures, and low-boiling amines (bp. in the range of $54-60{ }^{\circ} \mathrm{C}$ ) could be lost in the course of the process. The first set of reactions was performed by stirring racemic bromide $( \pm)-\mathbf{8}$ in an appropriate amine reagent for $24 \mathrm{~h}$ at room or elevated tempera- 
ture $\left(>60{ }^{\circ} \mathrm{C}\right)$. Unfortunately, all of these attempts failed to provide satisfactory results and led only to the recovery or the substantial decomposition of the starting material $( \pm)-\mathbf{8}$. We then turned our attention to the conventional protocol optimizing $N$-alkylation by screening several aprotic polar solvents $\left(\mathrm{CH}_{3} \mathrm{CN}, \mathrm{DMF}\right.$, dioxane and $\left.\mathrm{CH}_{2} \mathrm{Cl}_{2}\right)$ at room temperature or at heating, respectively. Under most of the aforementioned conditions, $( \pm)-\mathbf{8}$ proved to be reluctant to form respective tertiary amine products 9 or $\mathbf{1 0}$, and only in the case of substitution with $\mathrm{Me}_{2} \mathrm{NH}$ the reactions proceeded in both media $\left(\mathrm{CH}_{3} \mathrm{CN}\right.$ and dioxane), however sluggishly and somewhat low-yielding typically obtaining $( \pm)-9$ in less than $5 \%$. In the course of investigating why $( \pm)-\mathbf{8}$ failed to react with amines, we focused on employing various basic conditions $\left(\mathrm{EtN}_{3}, \mathrm{~K}_{2} \mathrm{CO}_{3}, n\right.$-BuLi), under which activation of the $N$-nucleophile might increase the reactivity and circumvent encountered drawbacks. Disappointingly, treatment of $( \pm)$-8 with $\mathrm{EtN}_{3}$ showed no positive effect on the reaction progress, and when $\mathrm{K}_{2} \mathrm{CO}_{3}$ or $n$-BuLi were applied it led only to exhaustive decomposition of the starting material $( \pm)-8$ producing a complex mixture. To improve the efficiency of the desired process, various catalytic conditions were subsequently evaluated. Initially, we decided to employ PTC-assisted amination in the similar manner to those reported by O'Meara [80] and Durst et al. [81], respectively. A number of different variants of these methods including use of $N$-benzyl- $N, N, N$-triethylammonium chloride [TEBA(Cl)] or dibenzo-18-crown-6 as the catalyst and a liquid-solid system comprising 1.6 equiv of grounded $\mathrm{NaOH}$ suspended in DMSO or a liquid-liquid systems composed of $50 \% \mathrm{NaOH}$ or $60 \% \mathrm{KOH}$ and the appropriate solvent $\left(\mathrm{CH}_{2} \mathrm{Cl}_{2}, \mathrm{DMSO}\right)$ stirred along with $\mathrm{Et}_{2} \mathrm{NH}$ at room or slightly increased temperature $\left(40{ }^{\circ} \mathrm{C}\right)$ have been studied. However, none of the attempted changes led to an improvement in the reaction progress. By the same token, another catalytic approach using solid $\mathrm{Ag}_{2} \mathrm{O}$ was adopted in accordance to a method proposed by D'Angeli et al. [82]. Since the authors of this report suggested that solid $\mathrm{Ag}_{2} \mathrm{O}$ behaves as both a Lewis acid and Brønsted base acting synergically on the investigated 2-bromo amides, we have assumed that the extension of this concept on our reaction could activate substrate $( \pm)$ 8 and thus promote the desired $N$-alkylation. And this time, application of $\operatorname{Ag}_{2} \mathrm{O}$ was not successful since this reaction has been plagued by the formation of an intractable mixture of side products. The resistance of $( \pm)-\mathbf{8}$ toward nucleophilic substitution in both studied catalytic systems (PTC- and $\mathrm{Ag}_{2} \mathrm{O}$-mediated approaches) may be explained by the fact that our substrate $( \pm)-\mathbf{8}$, in contrast to those described in the literature, lacks of the neighboring carbonyl group, which presumably favored the reported processes due to weakening of the carbon-bromine bond. Next, we aimed to investigate the amination of $( \pm)-\mathbf{8}$ using $\mathrm{Et}_{2} \mathrm{NH}$ in toluene medium hoping that the employment of this aprotic and less polar solvent could shift the equilibrium

toward the product formation if $( \pm)$-10 precipitated over the course of reaction in hydrobromide salt form. To our delight, when heating this reaction mixture at $110{ }^{\circ} \mathrm{C}$ for $96 \mathrm{~h}$ some progress has been observed. Therefore, to improve the efficiency of this process, our next attempt involved the increase in the operating temperature (up to $140{ }^{\circ} \mathrm{C}$ of an oil bath) as well as elongation of the reaction time, what finally provided $( \pm)-\mathbf{1 0}$ in $38 \%$ yield after 7 days. An extension of this condition for the reaction between $( \pm)-\mathbf{8}$ and $\mathrm{Me}_{2} \mathrm{NH}$ gave even a better result in terms of the product $( \pm)-9$ yield (47\%). However, when the above-performed reactions were repeated with optically active bromo derivatives $(R)-(+)-8(>99 \%$ ee) and $(S)-(-)-8(96 \%$ ee), it turned out that the respective products $(S)-(-)-9(84 \%$ ee) and $(R)-(+)-\mathbf{9}(92 \%$ ee) or $(S)-(-)-\mathbf{1 0}(90 \%$ ee $)$ and $(R)-(+)-\mathbf{1 0}(93 \%$ ee) were obtained with partial drop of the enantiomeric excess (Scheme 3). These facts plus the modest yields $(<50 \%)$ as well as long reactions time ( 7 days) limited this method as being a preparative one, and forced us to search for an alternative method.

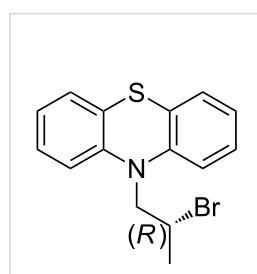

$(R)-(+)-8,>99 \%$ ee

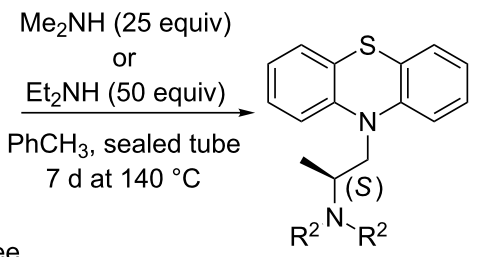

$\mathrm{R}^{2}=\mathrm{Me}:(S)-(-)-9,84 \%$ ee, $47 \%$ yield

$\mathrm{R}^{2}=\mathrm{Et}:(S)-(-)-10,90 \%$ ee, $38 \%$ yielc<smiles>CC(C)(Br)CN1c2ccccc2Sc2ccccc21</smiles>

(S)-(-)-8, 96\% ee

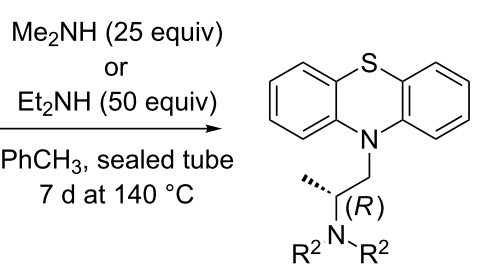

$\mathrm{R}^{2}=\mathrm{Me}:(R)-(+)-9,92 \%$ ee, $59 \%$ yield $\mathrm{R}^{2}=\mathrm{Et}:(R)-(+)-10,93 \%$ ee, $23 \%$ yield

Scheme 3: Amination of optically active bromo derivatives $(R)-(+)-8$ or (S)-(-)-8 in toluene.

Somewhat more surprisingly, the best results were obtained when the reaction was performed in $\mathrm{MeOH}$ similarly to the rivastigmine synthesis strategy published by Sethi and co-workers [83], but at higher temperature $\left(90^{\circ} \mathrm{C}\right.$ of an oil bath) since at reported $25{ }^{\circ} \mathrm{C}$ the reaction with substrate $( \pm)-\mathbf{8}$ did not occur. This modification led to obtain $( \pm)-9$ in yield of $38 \%$ and $( \pm)$-10 in yield of $71 \%$, respectively. A simple change of the solvent to methanol also drastically improved the rate as the reactions needed at least 3 days less when compared to those conducted in toluene and what is crucial at lower temperature. 
Moreover, under this conditions optically active substrate $(R)$ $(+)-8$ ( $>99 \%$ ee) underwent amination selectively almost without loss of optical purity affording unexpectedly enantioenriched products $(R)-(+)-\mathbf{9}(97 \%$ ee) and $(R)-(+)-\mathbf{1 0}(98 \%$ ee $)$ with reverse stereochemistry at a chiral carbon. Compared to the previously obtained products this seems to be more likely than the net retention (double inversion) occurred during this process. Their respective counterparts including $(S)-(-)-9$ $(94 \%$ ee) and $(S)-(-)-10$ (96\% ee) were obviously obtained in less enantiomerically pure forms as a consequence of preparing them from less enantiopure substrate $(S)-(-)-8(96 \%$ ee $)$ (Scheme 4).

The results of above described experiments can only be rationalized considering the formation of an intermediate aziridinium ion $(R)-\mathbf{1 3}$ upon heating in $\mathrm{MeOH}$, which is then attacked by amine at the more hindered carbon atom of the aziridine ring. These observations allowed us to propose the following plausible mechanism (Scheme 5), postulated mainly on the basis of the signs of specific rotation and the enantiomeric elution order from chiral HPLC, which were opposite to those corresponding to the appropriate products obtained when toluene was applied as a solvent (see Supporting Information File 1). This phenomenon was also confirmed by isolation of byproducts characteristic for this reaction mechanism including (2S)- $\mathrm{N}, \mathrm{N}$-dimethyl-2-(10H-phenothiazin-10yl)propan-1-amine (iso-promethazine) (S)-14 or $(2 S)-N, N$ diethyl-2-(10H-phenothiazin-10-yl)propan-1-amine (iso-ethopropazine) (S)-15 (depending on the amine used). What is even more compelling 10-[(2S)-2-methoxypropyl]-10H-pheno-

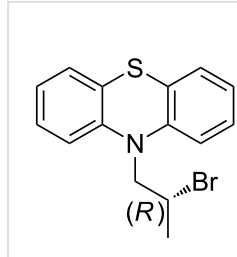

$(R)-(+)-8,>99 \%$ ee

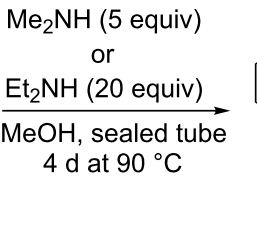

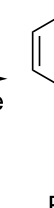

". $/(R)$

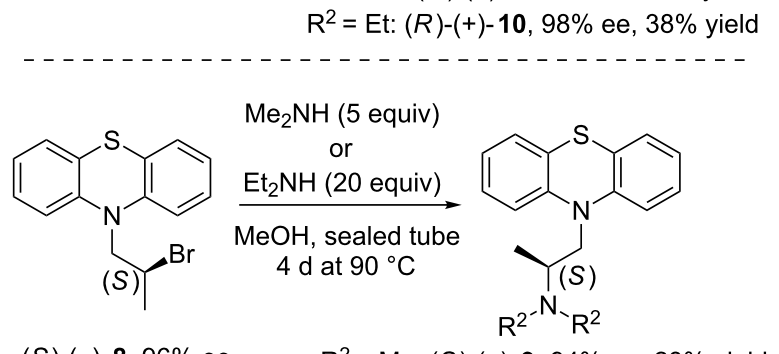

(S)-(-)-8, 96\% ee
$R^{2}=$ Me: $(S)-(-)-9,94 \%$ ee, $23 \%$ yield $R^{2}=$ Et: $(S)-(-)-10,96 \%$ ee, $31 \%$ yielc

Scheme 4: Amination of optically active bromo derivatives $(R)-(+)-8$ or $(S)-(-)-8$ in methanol.

thiazine $(S)-16$ and 10-[(2S)-1-methoxypropan-2-yl]-10Hphenothiazine $(S)-\mathbf{1 7}$ as a result of a competitive reaction between $(R)$-13 and methanol (Scheme 5) were isolated and characterized as well.

Moreover, an unexpected regioselectivity upon ring opening by amines has been observed. Apparently, this aziridinium salt $(R)$-13 is opened exclusively at the more hindered aziridine carbon atom since the respective products $(S)-(-)-9$ or $(S)-(-)-$ 10 (23-46\% yield) and $(S)-\mathbf{1 6}(<25 \%$ yield $)$ have been isolated

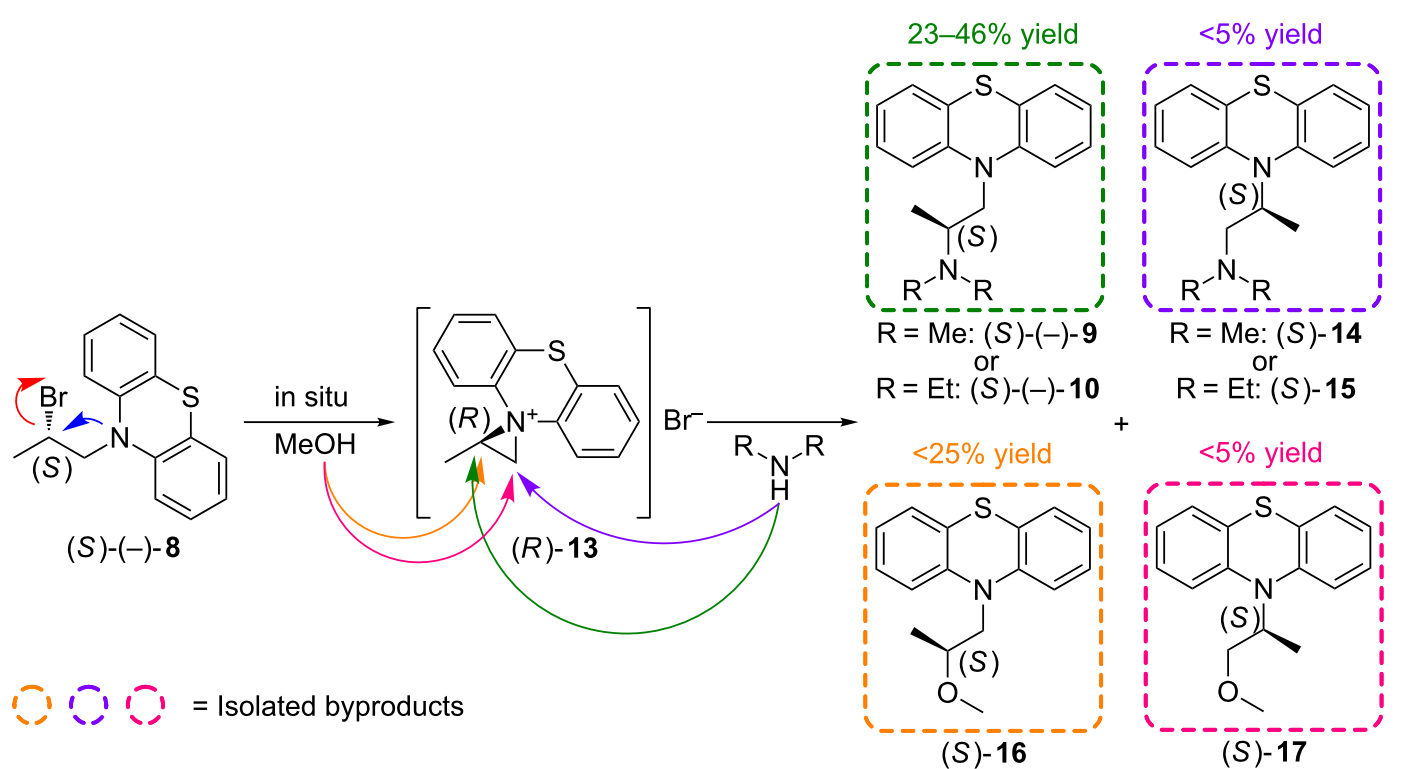

Scheme 5: The proposed reaction mechanism for amination of optically active (S)-(-)-8 in methanol. 
in majority, while yield of $(S)$-17 and both unwanted isomers $(S)$-14 or $(S)$-15 remained negligible $(<5 \%)$. The outcome of the reaction is quite interesting since the conversion of, i.e., $(S)$-bromide into the $(S)$-configurated product has proceeded with overall retention of configuration via regio- and stereospecific opening of the aziridinium ion $(R)-\mathbf{1 3}$ at the activated pseudo-benzylic position, where the partial positive charge $\left(\delta^{+}\right)$ is obviously better stabilized than at the neighboring carbon atom. This clearly suggests that electrostatic factors (interactions) are favored over steric hindrance effects giving the opportunity of a purely solvent-dependent stereodivergent synthesis of therapeutically active ingredients $\mathbf{9}$ and $\mathbf{1 0}$ in a highly stereoselective fashion.

In view of this findings, it appeared that deterioration of the enantiomeric excess of the both APIs isomers $[\Delta \%$ ee $=9-15$ for $(R)-(+)-8(>99 \%$ ee) and $\Delta \%$ ee $=3-4$ for $(S)-(-)-8$ $(96 \%$ ee) $]$ synthesized in toluene may be related to the fact that this process proceeded at least in part through the formation of activated aziridinium ion intermediate $(S) \mathbf{- 1 3}$ or $(R)-\mathbf{1 3}$ (net retention), and not only via direct attack of the amine on the appropriate bromo derivative $(R)-(+)-\mathbf{8}$ or $(S)-(-)-\mathbf{8}$ (single inversion). Toluene as an aprotic-lipophilic solvent is rather responsible for unfavorable conditions for the formation of aziridinium salt due to ineffective stabilization of the cationic species. Nevertheless some portions of the bromo derivative $\mathbf{8}$ most likely undergo intramolecular nucleophilic substitution by means of the neighboring amine moiety present in the phenothiazine ring, and by this affecting the optical purity of the products.

\section{Determination of the enantiomeric purity of promethazine $\mathbf{9}$ and ethopropazine $\mathbf{1 0}$}

In order to determine the enantiomeric excess of the final pharmaceutical products $\mathbf{9}$ and 10, we initially examined the chiral HPLC conditions proposed by Ponder et al. [52]. Among various HPLC columns studied in that paper, we have owned the Chiralcel OJ with cellulose-derived chiral stationary phase (CSP) consisting of cellulose tris(4-methylbenzoate) as chiral selector. Unfortunately, when using this column accordingly to Ponder's indications we could only separate promethazine $( \pm)-9$ base enantiomers (see Supporting Information File 1 for details). Since ethopropazine $( \pm)$-10 enantiomers were not resolvable on a Chiralcel OJ column under various HPLC conditions performed in the normal phase mode, we have opted to investigate several other polysaccharide type columns including Chiralcel OD-H, Chiralcel OJ-H, Chiralcel OJ-RH and Chiralpack IA. Unfortunately, all the studied chromatographic analyses led to failure as no signs of enantiomeric separations for $( \pm)$-10 were obtained. Therefore, we decided to investigate enantiomeric separation conditions applying a common NMR methodological approach, which assumes the use of a lanthanide-like chiral shift reagent (CSR) such as europium(III) tris[3-(heptafluoropropylhydroxymethylene)-(+)camphorate $\left[\mathrm{Eu}(\mathrm{hfc})_{3}\right]$ [84-86]. To our disappointment, the desirable enantiomeric shift difference magnitudes and enhanced spectral resolution for the studied $( \pm)$-10 were not achieved. Under these particular circumstances we were forced to undertake another strategy, which would provide highly accurate and rapid access to quantification of the enantiomeric excess of optically active ethopropazine 10. Finally, the assessment of enantiopurity of the synthesized $(S)-(-)-\mathbf{1 0}$ and $(R)-(+)-10$ were determined by HPLC, but using two serially connected Chiralcel OJ columns and mobile-phase system composed of $n$-hexane/tert-BuOH/Et ${ }_{3} \mathrm{~N}(98: 1.5: 0.5, \mathrm{v} / \mathrm{v} / \mathrm{v})$ at a flow rate of $1.1 \mathrm{~mL} / \mathrm{min}$ similarly to the method reported by Šinko et al. [57].

\section{Conclusion}

In summary, a straightforward chemoenzymatic preparation strategy of both highly enantioenriched enantiomeric forms of promethazine 9 (up to 97\% ee) and ethopropazine 10 (up to $98 \%$ ee), with the chirality being introduced by the action of lipases has been devised. An extensive screening revealed both Novozym 435 and Lipozyme TL IM lipase preparations to be capable of asymmetric enantioselective transesterification of racemic 1-(10H-phenothiazin-10-yl)propan-2-ol (( \pm$)-3)$. Kinetic resolution of $( \pm)-3$ using the respective enzymes, and vinyl acetate as the acylating agent have provided an efficient access to highly enantioenriched alcohols $(S)-(+)-5$ (>99\% ee) and $(R)-(-)-7$ (98\% ee) accomplished in high isolated yields (up to 95\%). Most of the critical enzymatic reaction factors such as medium, acyl group donor and operating time were investigated in depth to establish the most optimal biotransformation conditions. The obtained results of enzymatic reactions conducted in small scale (100 mg) were scaled-up with high correlation to a synthetically useful substrate amount of $3 \mathrm{~g}$ $( \pm)$-3 ( $0.4 \mathrm{M}$ concentration). Based on these findings, we can speculate that the developed procedure can facilitate a potential commercial application in the production of title drugs $\mathbf{9}$ and $\mathbf{1 0}$ with a good perspective in industrial scale since high conversions and excellent ee values can be achieved with low catalyst loadings. The ${ }^{1} \mathrm{H}$ NMR spectroscopic assignment of the absolute configuration of the slower reacting enantiomer (+)-5 of enzymatic KR was performed by means of a modified Mosher's methodology, and was supported by single-crystal X-ray diffraction (XRD), which both led up to the final conclusion that the employed lipase preparations exhibit $(R)$-stereopreference towards the enantiomers of resolved alcohol $( \pm)-3$. The products of the enzymatic transformations were functionalized en route to the title compounds via a two-step reaction sequence using the appropriate brominating agent $\left(\mathrm{PBr}_{3}\right)$, and 
subsequent amination of the thus-prepared halo derivative by means of respective aliphatic amines. A systematic investigation of the amine functionalization approach by examining various reaction parameters including solvents, catalysts, bases, additives, and operating temperatures revealed some unexpected results as the transformation of bromo derivative $\mathbf{8}$ is highly dependent on the proper choice of the reaction medium system. It turned out that in toluene solution a typical $\mathrm{S}_{\mathrm{N}} 2$ reaction is observed (single inversion), whereas in methanol an intramolecular cyclization occurred leading to aziridinium ionformation, which only then reacted with the amine giving the product of double inversion. In the case of reactions carried out in methanol only a negligible loss of the enantiomeric purity (94-97\% ee for 9 and $96-98 \%$ ee for $\mathbf{1 0}$ ) was observed, while the reactions conducted in toluene proceeded with higher level of deterioration in terms of enantiomeric excess values (84-92\% ee for 9 and $90-93 \%$ ee for $\mathbf{1 0})$.

\section{Supporting Information}

$$
\begin{aligned}
& \text { Supporting Information File } 1 \\
& \text { Complete experimental procedures and characterization } \\
& \text { data. } \\
& \text { [http://www.beilstein-journals.org/bjoc/content/ } \\
& \text { supplementary/1860-5397-10-322-S1.pdf] }
\end{aligned}
$$

\section{Acknowledgements}

The project was co-financed by The European Regional Development Fund under The Innovative Economy Operational Programme 2007-2013: 'Biotransformations for Pharmaceutical and Cosmetic Industry' POIG.01.03.01-00-158/09. These studies were partially supported by the Warsaw University of Technology, Faculty of Chemistry. Paweł Borowiecki would also like to gratefully acknowledge the financial support from the project: 'Development of science - the development of the region - scholarship and accompanying support for Mazovia postgraduate students' (Priority VIII Regional Economy; Human Resources Action 8.2 Knowledge Transfer; Inopportune 8.2.2 Regional Innovation Strategies, Operational Program Human Capital 2007-2013, European Union fund).

\section{References}

1. Carey, J. S.; Laffan, D.; Thomson, C.; Williams, M. T. Org. Biomol. Chem. 2006, 4, 2337-2347. doi:10.1039/b602413k

2. Mentel, M.; Blankenfeldt, W.; Breinbauer, R. Angew. Chem., Int. Ed. 2009, 48, 9084-9087. doi:10.1002/anie.200902997

3. Kasprzyk-Hordern, B. Chem. Soc. Rev. 2010, 39, 4466-4503. doi:10.1039/c000408c

4. Liese, A.; Seelbach, K.; Wandrey, C., Eds. Industrial Biotransformations, 2nd ed.; Wiley-VCH: Weinheim, 2006.
5. Rasor, J. P.; Voss, E. Appl. Catal., A 2001, 221, 145-158. doi:10.1016/S0926-860X(01)00804-3

6. Ran, N.; Zhao, L.; Chen, Z.; Tao, J. Green Chem. 2008, 10, 361-372. doi:10.1039/b716045c

7. Rodrigues, R. C.; Fernandez-Lafuente, R. J. Mol. Catal. B: Enzym. 2010, 64, 1-22. doi:10.1016/j.molcatb.2010.02.003

8. Wenda, S.; IIIner, S.; Mell, A.; Kragl, U. Green Chem. 2011, 13, 3007-3047. doi:10.1039/c1gc15579b

9. Muñoz Solano, D.; Hoyos, P.; Hernáiz, M. J.; Alcántara, A. R.; Sánchez-Montero, J. M. Bioresour. Technol. 2012, 115, 196-207. doi:10.1016/j.biortech.2011.11.131

10. Meyer, H.-P.; Eichhorn, E.; Hanlon, S.; Lütz, S.; Schürmann, M.; Wohlgemuth, R.; Coppolecchia, R. Catal. Sci. Technol. 2013, 3, 29-40. doi:10.1039/c2cy20350b

11. Schoffers, E.; Golebiowski, A.; Johnson, C. R. Tetrahedron 1996, 52, 3769-3826. doi:10.1016/S0040-4020(95)01021-1

12. Faber, K., Ed. Biotransformations in Organic Chemistry: A Textbook, 6th ed.; Springer Verlag: New York, NY, 2011.

13. García-Urdiales, E.; Alfonso, I.; Gotor, V. Chem. Rev. 2011, 111, PR110-PR180. doi:10.1021/cr100330u

14. Wong, C.-H.; Whitesides, G. M., Eds. Enzymes in Synthetic Organic Chemistry; Tetrahedron Organic Chemistry, Vol. 12; Pergamon: Oxford, 1994.

15. Drauz, K.; Waldmann, H., Eds. Enzyme Catalysis in Organic Synthesis; VCH Verlagsgesellschaft mbH: Weinheim, 1995.

16. Sugai, T. Curr. Org. Chem. 1999, 3, 373-406.

17. Davis, B. G.; Boyer, V. Nat. Prod. Rep. 2001, 18, 618-640. doi:10.1039/b003667f

18. Hudlicky, T.; Reed, J. W. Chem. Soc. Rev. 2009, 38, 3117-3132. doi:10.1039/b901172m

19. Borges, K. B.; de Souza Borges, W.; Durán-Patrón, R.; Tallarico Pupo, M.; Sueli Bonato, P.; Gonzaléz Collado, I. Tetrahedron: Asymmetry 2009, 20, 385-397. doi:10.1016/j.tetasy.2009.02.009

20. Hollmann, F.; Arends, I. W. C. E.; Holtmann, D. Green Chem. 2011, 13, 2285-2314. doi:10.1039/c1gc15424a

21. Zhang, H.; Ren, J.; Wang, Y.; Sheng, C.; Wu, Q.; Diao, A.; Zhu, D. Tetrahedron 2013, 69, 184-189. doi:10.1016/j.tet.2012.10.047

22. Schulze, B.; Wubbolts, M. G. Curr. Opin. Biotechnol. 1999, 10, 609-615. doi:10.1016/S0958-1669(99)00042-7

23. Liese, A.; Villela Filho, M. Curr. Opin. Biotechnol. 1999, 10, 595-603. doi:10.1016/S0958-1669(99)00040-3

24. Panke, S.; Held, M.; Wubbolts, M. Curr. Opin. Biotechnol. 2004, 15, 272-279. doi:10.1016/j.copbio.2004.06.011

25. Patel, R. N. Coord. Chem. Rev. 2008, 252, 659-701. doi:10.1016/j.ccr.2007.10.031

26. Tao, J.; Xu, J.-H. Curr. Opin. Chem. Biol. 2009, 13, 43-50. doi:10.1016/j.cbpa.2009.01.018

27. Nestl, B. M.; Nebel, B. A.; Hauer, B. Curr. Opin. Chem. Biol. 2011, 15, 187-193. doi:10.1016/j.cbpa.2010.11.019

28. Clouthier, C. M.; Pelletier, J. N. Chem. Soc. Rev. 2012, 41, 1585-1605. doi:10.1039/c2cs15286j

29. Simon, R. C.; Mutti, F. G.; Kroutil, W. Drug Discovery Today: Technol. 2013, 10, e37-e44. doi:10.1016/j.ddtec.2012.08.002

30. Huisman, G. W.; Collier, S. J. Curr. Opin. Chem. Biol. 2013, 17, 284-292. doi:10.1016/j.cbpa.2013.01.017

31. Tokoshima, D.; Hanaya, K.; Shoji, M.; Sugai, T. J. Mol. Catal. B: Enzym. 2013, 97, 95-99. doi:10.1016/j.molcatb.2013.07.021 
32. Itoh, T.; Takagi, Y.; Tsukube, H. J. Mol. Catal. B: Enzym. 1997, 3, 259-270. doi:10.1016/S1381-1177(97)00007-6

33. Gandhi, N. N. J. Am. Oil Chem. Soc. 1997, 74, 621-634. doi:10.1007/s11746-997-0194-x

34. Kazlauskas, R. J.; Bornscheuer, U. T. Biotransformation 1. In Biotransformations with lipases, Biotechnology, 2nd ed.; Kelly, D. R., Ed.; Wiley-VCH: Weinheim, 1998; Vol. 8, pp 37-191.

35. Jaeger, K.-E.; Dijkstra, B. W.; Reetz, M. T. Annu. Rev. Microbiol. 1999, 53, 315-351. doi:10.1146/annurev.micro.53.1.315

36. Jaeger, K.-E.; Eggert, T. Curr. Opin. Biotechnol. 2002, 13, 390-397. doi:10.1016/S0958-1669(02)00341-5

37. Lambusta, D.; Nicolosi, G.; Patti, A.; Sanfilippo, C. J. Mol. Catal. B: Enzym. 2003, 22, 271-277. doi:10.1016/S1381-1177(03)00042-0

38. Ghanem, A. Tetrahedron 2007, 63, 1721-1754. doi:10.1016/j.tet.2006.09.110

39. Section C Lipases. In Industrial Enzymes: Structure, Function and Applications; Polaina, J.; MacCabe, A. P., Eds.; Springer, 2007; pp 263-341.

40. Lednicer, D.; Mitscher, L. A. Organic Chemistry of Drug Synthesis; John Wiley \& Sons, 1977; Vol. 1.

41. Taurand, G. Phenothiazine and Derivatives. Ullmann's Encyclopedia of Industrial Chemistry; Wiley-VCH: Weinheim, 2005.

42. Halpern, B. N.; Ducrot, R. Compt. Rend. Soc. Biol. 1946, 140, 361-363.

43. Reynolds, J. E. F., Ed. Martindale: the extra pharmacopoeia, 29th ed.; Pharmaceutical Press: London, 1989.

44. Yanai, K. Clin. Neurophysiol. 2012, 123, 633-634. doi:10.1016/j.clinph.2011.09.005

45. Biel, J. H.; Martin, Y. C. Organic synthesis as a source of new drugs. In Drug Discovery, Advances in Chemistry Series no. 108; Gould, R. F., Ed.; American Chemical Society: Washington, DC, 1971; p 81.

46. Nauta, W. T.; Rekker, R. F. Structure-activity relationships of H1receptor antagonists. In Handbook of Experimental Pharmacology; Rocha e Silva, M., Ed.; Springer-Verlag: New York, 1978; pp $215 \mathrm{ff}$.

47. Toldy, L.; Vargha, L.; Toth, I. Acta Chim. Acad. Sci. Hung. 1959, 19, 273.

48. McDonough, J.; Dixon, H.; Niño, J. Intranasal Drug Delivery Technology for space motion sickness, 01-9303. Southwest Research Institute, inclusive dates 004/01/2002; http://www.swri.org/3pubs/IRD2003/Synopses/019303.htm

49. Boland, E. J.; McDonough, J. Phenothiazine enantiomers as agents for the prevention of bone loss. WO Patent WO2004/110458 A1, Dec 23, 2004.

50. Boland, E. J. Phenothiazine enantiomers as agents for the prevention of bone loss. U.S. Patent US2006/0258650 A1, Nov 16, 2006.

51. Šinko, G.; Kovarik, Z.; Reiner, E.; Simeon-Rudolf, V.; Stojan, J. Biochimie 2011, 93, 1797-1807. doi:10.1016/j.biochi.2011.06.023

52. Ponder, G. W.; Butram, S. L.; Adams, A. G.; Ramanathan, C. S.; Stewart, J. T. J. Chromatogr., A 1995, 692, 173-182. doi:10.1016/0021-9673(94)00997-N

53. Chiari, M.; Cretich, M.; Desperati, V.; Marinzi, C.; Galbusera, C.; De Lorenzi, E. Electrophoresis 2000, 21, 2343-2351. doi:10.1002/1522-2683(20000701)21:12<2343::AID-ELPS2343>3.0.C O;2-C

54. Bosáková, Z.; Kloučková, I.; Tesařová, E. J. Chromatogr., B 2002, 770, 63-69. doi:10.1016/S0378-4347(01)00559-X

55. Lin, C.-E.; Liao, W.-S.; Cheng, H.-T.; Kuo, C.-M.; Liu, Y.-C. Electrophoresis 2005, 26, 3869-3877. doi:10.1002/elps.200500087
56. Martínez-Gómez, M. A.; Sagrado, S.; Villanueva-Camañas, R. M.; Medina-Hernández, M. J. Anal. Chim. Acta 2007, 582, 223-228. doi:10.1016/j.aca.2006.09.036

57. Šinko, G.; Novak, P.; Žiher, D.; Vinković, V.; Šunjić, V.; Simeon-Rudolf, V. Enantiomer 2002, 7, 149-156. doi:10.1080/10242430212188

58. Puthca, L.; McDonough, J.; Boland, E. J.; Dixon, H.; Persyn, J. T.; Vasishtha, N. Compositions a liberation progressive et son procede d'utilisation. WO Patent WO2003/105811 A2, Dec 24, 2003.

59. Clement, B.; Beckett, A. H. Arch. Pharm. 1981, 314, 716-722. doi:10.1002/ardp.19813140812

60. Dahlbom, R. Acta Chem. Scand. 1949, 3, 247-255. doi:10.3891/acta.chem.scand.03-0247

61. Gozlan, I.; Ladkani, D.; Halpern, M.; Rabinovitz, M.; Avnir, D. J. Heterocycl. Chem. 1984, 21, 613-614. doi:10.1002/jhet.5570210271

62. Gomurashvili, Z.; Crivello, J. V. Macromolecules 2002, 35, 2962-2969. doi:10.1021/ma0119272

63. Hsu, Y.-C.; Gan, K.-H.; Yang, S.-C. Chem. Pharm. Bull. 2005, 53, 1266-1269. doi:10.1248/cpb.53.1266

64. Porumb, D.; Lovász, T.; Răchită, G.; Cristea, C.; Găină, L.; Silaghi-Dumitrescu, L. Rev. Roum. Chim. 2010, 55, 879-884.

65. Abreu, A. R.; Costa, I.; Rosa, C.; Ferreira, L. M.; Lourenço, A.; Santos, P. P. Tetrahedron 2005, 61, 11986-11990. doi:10.1016/j.tet.2005.09.064

66. Carrea, G.; Riva, S. Angew. Chem., Int. Ed. 2000, 39, 2226-2254. doi:10.1002/1521-3773(20000703)39:13<2226::AID-ANIE2226>3.0.CO ;2-L

67. Laane, C.; Boeren, S.; Vos, K.; Veeger, C. Biotechnol. Bioeng. 1987, 30, 81-87. doi:10.1002/bit.260300112

68. Janssen, A. E. M.; van der Padt, A.; van't Riet, K. Biotechnol. Bioeng. 1993, 42, 953-962. doi:10.1002/bit.260420806

69. Janssen, A. E. M.; van der Padt, A.; van Sonsbeek, H. M.; van't Riet, K. Biotechnol. Bioeng. 1993, 41, 95-103. doi:10.1002/bit.260410113

70. Chen, C. S.; Fujimoto, Y.; Girdaukas, G.; Sih, C. J. J. Am. Chem. Soc. 1982, 104, 7294-7299. doi:10.1021/ja00389a064

71. Seco, J. M.; Quiñoá, E.; Riguera, R. Tetrahedron: Asymmetry 2001, 12, 2915-2925. doi:10.1016/S0957-4166(01)00508-0

72. Borowiecki, P.; Poterała, M.; Maurin, J.; Wielechowska, M.; Plenkiewicz, J. ARKIVOC 2012, No. 8, 262-281. doi:10.3998/ark.5550190.0013.823

73. Borowiecki, P.; Milner-Krawczyk, M.; Brzezińska, D.; Wielechowska, M.; Plenkiewicz, J. Eur. J. Org. Chem. 2013, 712-720. doi:10.1002/ejoc.201201245

74. Borowiecki, P.; Milner-Krawczyk, M.; Plenkiewicz, J. Beilstein J. Org. Chem. 2013, 9, 516-525. doi:10.3762/bjoc.9.56

75. Borowiecki, P.; Fabisiak, M.; Ochal, Z. Tetrahedron 2013, 69 , 4597-4602. doi:10.1016/j.tet.2013.04.014

76. Latypov, S. K.; Seco, J. M.; Quiñoá, E.; Riguera, R. J. Org. Chem. 1995, 60, 504-515. doi:10.1021/jo00108a008

77. Kazlauskas, R. J.; Weissfloch, A. N. E.; Rappaport, A. T.; Cuccia, L. A. J. Org. Chem. 1991, 56, 2656-2665. doi:10.1021/jo00008a016

78. Edwards, M. L.; Stemerick, D. M.; McCarthy, J. R. Tetrahedron Lett. 1990, 31, 3417-3420. doi:10.1016/S0040-4039(00)97411-2

79. Busto, E.; Gotor-Fernández, V.; Gotor, V. J. Org. Chem. 2012, 77, 4842-4848. doi:10.1021/jo300552v

80. O'Meara, J. A.; Gardee, N.; Jung, M.; Ben, R. N.; Durst, T. J. Org. Chem. 1998, 63, 3117-3119. doi:10.1021/jo9712714

81. Ben, R. N.; Durst, T. J. Org. Chem. 1999, 64, 7700-7706. doi:10.1021/j09811625 
82. D'Angeli, F.; Marchetti, P.; Bertolasi, V. J. Org. Chem. 1995, 60, 4013-4016. doi:10.1021/jo00118a017

83. Sethi, M. K.; Bhandya, S. R.; Maddur, N.; Shukla, R.; Kumar, A.; Mittapalli, V. S. N. J. Tetrahedron: Asymmetry 2013, 24, 374-379. doi:10.1016/j.tetasy.2013.01.023

84. McCreary, M. D.; Lewis, D. W.; Wernick, D. L.; Whitesides, G. M J. Am. Chem. Soc. 1974, 96, 1038-1054. doi:10.1021/ja00811a016

85. Hanna, G. M. J. Pharm. Biomed. Anal. 1997, 15, 1805-1811. doi:10.1016/S0731-7085(96)02042-0

86. Kagawa, M.; Machida, Y.; Nishi, H.; Haginaka, J. J. Pharm. Biomed. Anal. 2005, 38, 918-923. doi:10.1016/j.jpba.2005.06.005

\section{License and Terms}

This is an Open Access article under the terms of the Creative Commons Attribution License

(http://creativecommons.org/licenses/by/2.0), which permits unrestricted use, distribution, and reproduction in any medium, provided the original work is properly cited.

The license is subject to the Beilstein Journal of Organic Chemistry terms and conditions:

(http://www.beilstein-journals.org/bjoc)

The definitive version of this article is the electronic one which can be found at: doi:10.3762/bjoc. 10.322 